NBER WORKING PAPER SERIES

\title{
ESTIMATION OF A DYNAMIC AUCTION GAME
}

\author{
Mireia Jofre-Bonet \\ Martin Pesendorfer \\ Working Paper 8626 \\ http://www.nber.org/papers/w8626 \\ NATIONAL BUREAU OF ECONOMIC RESEARCH \\ 1050 Massachusetts Avenue \\ Cambridge, MA 02138 \\ December 2001
}

\begin{abstract}
An earlier version of the paper was circulated under the title "Bidding Behavior in a Repeated Procurement Auction". We are grateful to two referees and an editor for detailed and helpful comments. We thank Dirk Bergemann and Ariel Pakes for numerous discussions at early stages of the research, and Lanier Benkard, Phil Haile, Frode Sten and Jonathan Levin for their useful comments as discussants of this paper. We also thank seminar participants at Boston University, Brown, Carnegie Mellon, Columbia, Florence, Georgetown, Harvard, Hebrew University, Michigan, Rochester, Upenn, Yale, Wharton, the 1999 EEA meetings, the 1999 Econometric Society meetings, a Cowles conference at Yale, the 2000 NBER 10 meetings and the 1999 CEPR meetings in Toulouse for helpful comments. Kenneth Chan and Nancy Epling provided excellent research assistance. Martin Pesendorfer gratefully acknowledges financial support from NSF grant SES 9811134. We are also grateful to the California Department of Transportation for making the data available to us. The views expressed herein are those of the authors and not necessarily those of the National Bureau of Economic Research.
\end{abstract}

(C) 2001 by Mireia Jofre-Bonet and Martin Pesendorfer. All rights reserved. Short sections of text, not to exceed two paragraphs, may be quoted without explicit permission provided that full credit, including (C) notice, is given to the source. 
Estimation of a Dynamic Auction Game

Mireia Jofre-Bonet and Martin Pesendorfer

NBER Working Paper No. 8626

December 2001

JEL No. D44, D82

\begin{abstract}
This paper proposes an estimation method for a repeated auction game under the presence of capacity contraints. The estimation strategy is computationally simple as it does not require solving for the equilibrium of the game. It uses a two stage approach. In the first stage the distribution of bids conditional on state variables is estimated using data on bids, bidder characteristics and contract characteristics. In the second stage, an expression of the expected sum of future profits based on the distribution of bids is obtained, and costs are inferred based on the first order condition of optimal bids.

We apply the estimation method to repeated highway construction procurement auctions in the state of California between May 1996 and May 1999. In this market, previously won uncompleted contracts reduce the probability of winning further contracts. We quantify the effect of intertemporal constraints on bidders' costs and on bids. Due to the intertemporal effect and also to bidder asymmetry, the auction can be inefficient. Based on the estimates of costs, we quantify efficiency losses.
\end{abstract}

Mireia Jofre-Bonet

Department of Public Health

Yale University

P.O. Box 208034

New Haven, CT 06520-8034

mireia.jofre-bonet@yale.edu
Martin Pesendorfer

Department of Economics

Yale University

P.O. Box 208264

New Haven, CT 06520-8264

and NBER

martin.pesendorfer@yale.edu 


\section{INTRODUCTION}

Most of the literature on empirical estimation of auctions assumes a static auction setting. Parsch (1992), Laffont, Ossard and Vuong (1995), Guerre, Perrigne and Vuong (2000), and others develop an empirical approach to quantify informational uncertainty in static auction games. On the contrary, there is little empirical work on dynamic auction games ${ }^{2}$ or dynamic oligopoly games. ${ }^{3}$

This paper proposes an estimation method for dynamic oligopoly games. The method is computationally simple as it does not require solving for the equilibrium strategies of the game. We apply the method to estimate a repeated first-price auction game under the presence of capacity contraints.

We observe data on bids, contracts' characteristics and bidders' state variables. The estimation problem is how to infer privately known costs. We propose an estimation method that infers costs based on the first order condition of optimal bids of the repeated bidding game. We assume that observed data is generated by equilibrium play and estimate the distribution of bids conditional on state variables. Our crucial idea is that the expected discounted sum of future profits, which enter the first order condition, can be written looking forward and depending entirely on the distribution of bidders' bid choices. ${ }^{4}$ In particular, the resulting expression of the value function can be written as a linear equation system which can be easily solved numerically. With the value function at hand, costs are inferred based on the first order condition.

2 Laffont and Robert (1999) and Donald, Paarsch and Robert (1997) analyze finitely repeated auctions. Laffont and Robert consider a sequence of auctions in which, at each stage, an identical object is sold. Their model generates complex intra-day dynamics which are applied to data on eggplant auctions. Donald, Paarsch and Robert consider a model in which a finite number of objects are sold in a sequence of ascending-price auctions. They estimate the model using data on the sales of Siberian timber-export permits.

3 Pakes (1994) summarizes the literature on estimation in dynamic games.

4 A related estimation strategy of the value function is employed by Hotz and Miller (1993). They approximate the value function with discrete choices using estimates of choice probabilities. Their framework differs from ours in a number of ways: First, they consider a single agent dynamic decision problem. Second, they restrict their attention to discrete actions. Finally, they do not model informational constraints. 
Our approach builds partially on the two stage approach that Elyakime, Laffont, Loisel and Vuong (1994), and Guerre, Perrigne and Vuong (2000) develop for static models. These papers estimate the distribution of equilibrium actions based on bid data. In equilibrium, the distribution function estimates summarize bidders' beliefs and can be used to infer bidders' valuations based on the first order condition of optimal actions. The main contribution of our paper is to extend the estimation method to dynamic games.

In work in progress, Berry and Pakes (2000) consider a related estimation strategy for dynamic games. The distinguishing feature of their approach is to consider an alternative representation of the value function in which the expected sum of future profits is replaced with a sequence of future profit realizations. In dynamic auction games, this representation is less attractive because profits are not observed and cannot be expressed indirectly, from observed bids, without knowing the equilibrium bid functions.

We apply our method to repeated procurement auctions for highway paving contracts. In this setting, previously won uncompleted contracts may affect the ability to win further contracts. Two distinct effects may arise: First, since the duration of highway paving contracts is a number of months, winning a large contract may commit some of the bidder's machines and paving resources for the duration of the contract. Although rental of additional equipment is available, this may increase total cost. Second, an experience effect may arise, since supplying services on a large contract may give a bidder the necessary expertise to conduct further services. The expertise effect may lower the cost for future contracts.

The results of our estimation using highway procurement data show that capacity constraints do affect firms' bidding strategies. In particular, the cost of taking on an additional contract is increasing in backlog. The increase in costs resulting from a larger than average backlog seems to cancel out any cost-reducing expertise effects, if they exist. Based on the estimates of costs, we quantify efficiency losses.

Our estimation method requires that bidders completely understand the auction environment and that our estimates of winning probabilities correctly measure bidders' perceived odds of winning. Beyond some general regularity predictions, we are not able to assess the adequacy of our behavioral assumptions. The main reason is that our data do not contain in- 
formation about bidders' assessments. In particular, we do not observe bidders' perceived odds of winning a contract, nor bidders' actual contract costs. More detailed information about ex post realized outcomes is observed in outer continental shelf auctions studied by Hendricks and Porter (1988) and Porter (1995) among others. Hendricks and Porter convincingly show that auction models provide accurate predictions of outcomes and that the behavioral assumptions of game theoretic models are satisfied.

The paper is organized as follows: Section 2 describes the bidding model. Section 3 introduces the econometric method. The section addresses several issues: First, how to estimate the distribution of bids conditional on bidders' state variables and contract characteristics. Second, how to estimate the expected future discounted payoff of bidders based on estimates of the bid distribution function. Third, how to infer costs using the first order condition of optimal bids in the repeated game. Finally, conditions are provided under which the bidding model's parameters are identified.

Section 4 describes the industry and the data. We examine data on highway procurement contracts in California. The descriptive data analysis suggests the presence of capacity constraints. Estimates of the probability of submitting a bid reveal that bidders with low backlog levels are about twice as likely to submit a bid than bidders with high backlog levels.

Section 5 presents the estimates of the bidding model. The distribution of costs exhibits the expected properties of capacity constraints. To illustrate the estimates, we evaluate the estimated bid and cost distributions at average sample characteristics. The distribution of bids and costs at low backlog values stochastically dominates (in the first order sense) the distribution at high backlog values. Moreover, increasing the backlog appears to monotonically decrease the discounted sum of future profits.

Section 6 reports the effect of backlog on the expected price paid by the auctioneer and the effect of backlog on the expected auction return to individual bidders. In addition, we compare the observed outcome to a cost minimizing allocation of contracts. We conduct experiments to assess the magnitude of efficiency losses. Finally, section 7 provides some discussion and concludes. 


\section{THE BIDDING MODEL}

This section describes the bidding model. We begin with a general description of the game. We describe the sequencing of events in the stage game and the assumptions entering each event. We then describe the law of motion of the state variables and the payoffs to bidders. We conclude the section with some remarks on the existence of a value function representation of payoffs and the existence of markovian equilibria of the game.

The bidding model that we take to the data has the following features: Time is discrete with an infinite horizon, $t=0,1,2, \ldots$. There are two types of bidders: regular and fringe bidders. Fringe bidders have a short life and exit in the period they entered. ${ }^{5}$ Regular bidders stay in the game forever. The set of regular bidders is denoted by $\{1, \ldots, n\}$ and the set of fringe bidders in period $t$ is denoted by $\left\{n+1, \ldots, n_{F}^{t}\right\}$.

The Stage Game: In every period $t$ the buyer offers a single contract for sale. The sale can be described by the following sequence of events: First, the characteristics of the contract are revealed to all bidders. Second, bidders learn their costs privately. Third, bidders may submit bids. Fourth, the seller awards the contract to the low bidder - ties are resolved with the flip of a coin. The events in the stage game have the following features:

The contract characteristics, $s_{0}^{t}$, are drawn independently and identically from the exogenous probability distribution function, $F_{0}($.$) , with finite support S_{0}$. Future contract characteristics are assumed to be unknown to bidders. ${ }^{6}$ The contract characteristics, $s_{0}^{t}$, include the physical attributes of the contract such as the contract size and duration, as well as the

5 We observe a number of bidders that submit a bid only once, or a small number of times. On the other hand, we observe a number of bidders that submit bids frequently. To account for this difference, we classify firms into two groups: Regular bidders, which are the largest 10 firms in dollar value won and with at least 80 bids submitted; and Fringe bidders which are the remaining firms.

6 In highway procurement auctions future projects are not known to bidders. Only a short period in advance do project descriptions become available. The length of the announcement period ranges between 4 and 10 weeks. Information on the specification of immediately upcoming projects could be incorporated into the model by including the information on upcoming contracts as additional state variables. However, due to the added computational burden of additional state variables, we decided to ignore this feature of the data, and assume that contract characteristics become known in the period of the letting. 
total number of bidders that are active in the period, $n_{F}^{t}$, and the fixed (non-random) reserve price of the seller $R^{t}$.

Costs: Each bidder $i$ learns her cost for the contract, $c_{i}^{t}$, after the contract characteristics are revealed. The cost is privately known and independently distributed conditional on state variables. The cost of a regular bidder $i$ is drawn from the conditional distribution function $F\left(. \mid s_{0}^{t}, s_{i}^{t}, s_{-i}^{t}\right)$ with support $\left[\underline{C}\left(s_{0}^{t}, s_{i}^{t}, s_{-i}^{t}\right), \bar{C}\left(s_{0}^{t}, s_{i}^{t}, s_{-i}^{t}\right)\right]$, where $s_{i}^{t} \in \mathcal{S}_{i}$, with $\mathcal{S}_{i}$ finite, denotes a vector of state variables for bidder $i$ and $s_{-i}^{t}$ denotes the vector of other bidders state variables $\left(s_{1}^{t}, \ldots, s_{i-1}^{t}, s_{i+1}^{t}, \ldots, s_{n}^{t}\right) .{ }^{7}$ We sometimes use the symbol $s^{t}$ to denote the vector of all regular bidders' state variables with $s^{t} \in \mathcal{S}$ and $\mathcal{S}=\times_{i=1}^{n} \mathcal{S}_{i}$. We sometimes write $\left(s_{i}^{t}, s_{-i}^{t}\right)$ to indicate that the state vector is evaluated from bidder $i$ 's perspective. Bidder $i$ 's state vector $s_{i}$ includes a list of the sizes of all uncompleted projects that she has won in the past and the time left to complete each of them. Specifically, $s_{i}$ records the remaining size in dollars and the number of days left until completion of each project previously won by bidder $i$. We assume that both $s_{0}^{t}$ and $s^{t}$ are observable to all bidders and to the econometrician. We do not consider heterogeneity that is known to the bidders but not known to the econometrician. The distribution of costs has a continuous density function $f\left(. \mid s_{0}^{t}, s_{i}^{t}, s_{-i}^{t}\right)$. Similarly, the cost of a fringe bidder is drawn from a distribution function $F_{f}\left(. \mid s_{0}^{t}, s^{t}\right)$ with associated continuous density function $f_{f}\left(. \mid s_{0}^{t}, s^{t}\right)$ and support $\left[\underline{C}\left(s_{0}^{t}, s^{t}\right), R^{t}\right]$. The support assumption ensures that fringe bidders submit a bid.

Conditional independence of contract characteristics and cost realizations is the crucial assumption in the data generating process. It permits us to adopt the framework of markov dynamic decision processes. The role of conditional independence is discussed further in Rust

7 An alternative two step process in which costs are learned is considered in Hendricks, Pinske and Porter (2000). Hendricks, Pinske and Porter assume that bidders decide, initially, whether to acquire private information or not, and only bidders that decide to acquire information will potentially participate in the auction. This approach appears reasonable for auction environments where it can be rather costly to obtain an estimate about value of the item. Our data do not contain information on information acquisition decisions that would allow us to identify such a two step model. In addition, the two step approach appears less plausible for highway paving jobs in which most bidders have a relatively accurate assessment about the opportunity cost of using their paving resources. The cost uncertainty in highway bidding arises because the bidder's opportunity costs are not known to other bidders. 
(1994).

Bids: Each bidder may submit a bid, $b$, which is the price at which the bidder is willing to provide the service. The bidder with the lowest bid wins the contract and receives her bid. All agents are risk neutral. Ties are resolved by the flip of a coin. The buyer rejects bids above the reserve price $R^{t}$.

The transition function of the state variable, $\omega: S_{0} \times \mathcal{S} \times\left\{0,1,2, \ldots, \max \left(n_{F}^{t}\right)\right\} \longrightarrow \mathcal{S}$, is a deterministic function of the contract characteristics, the state variables, and the identity of the low bidder - where identity 0 indicates that nobody won the auction. ${ }^{8}$ As described above, the bidders' state variables include the sizes of all the projects left to do and the time remaining until their completion. Unfortunately, the data do not include information on the pattern in which projects are completed over time, but only the contract scheduled completion date. We assume that, at every point of time, an equal share of the project is completed and that contracts are completed as planned. ${ }^{9}$ Let the $i$ th component of the transition function $\omega$ measure the sizes and remaining times of all the project left to do for bidder $i$. It can be written as:

$$
\omega_{i}\left(s_{0}, s, j\right)= \begin{cases}\left(z_{0}, \tau_{0},\left(\frac{\tau_{j}^{t}-1}{\tau_{j}^{t}} \cdot z_{j}^{t}, \tau_{j}^{t}-1\right)_{j \in J_{i}^{t}}\right) & \text { if } j=i \\ \left(\frac{\tau_{j}^{t}-1}{\tau_{j}^{t}} \cdot z_{j}^{t}, \tau_{j}^{t}-1\right)_{j \in J_{i}^{t}} & \text { otherwise }\end{cases}
$$

where $\left(z_{j}^{t}, \tau_{j}^{t}\right)_{j \in J_{i}^{t}} \in s_{i}^{t}$ is a component of bidder $i$ th state vector; $J_{i}^{t}$ denotes the set of previously won and uncompleted projects of bidder $i ; z_{j}^{t}$ denotes the size of project $j$; and, $\tau_{j}^{t}$ its remaining time until completion. Given the linearity assumption regarding the completion of projects, for each project $j \in J_{i}^{t}$, the size carried over to next period, $z_{j}^{t+1}$, equals $\frac{\tau_{j}^{t}-1}{\tau_{j}^{t}} \cdot z_{j}^{t}$, and the remaining time until completion $\tau_{j}^{t+1}$ equals $\tau_{j}^{t}-1$. If contract at period $t$ is won by bidder

8 Note that the identity of the low bidder can be deduced from the vector of submitted bids. Thus, an equivalent formulation of the state's transition function uses the vector of bids by all bidders instead of the identity of the low bidder.

9 Section 8-1.07, "Liquidated Damages", of the Standard Specifications (1999) of the Department of Transportation of California specifies that unjustified delays may come at a high cost to the contractor. The cost of delays for contracts during our sample period ranges between hundreds of dollars to thousands of dollars per day. 
$i$, it is added to the set $J_{i}^{t+1}$ with the initial size and time until completion taken from the contract's characteristics $\left(z_{0}, \tau_{0}\right) \in s_{0}$.

We introduce a common discount factor parameter, $\beta \in(0,1)$, that measures firms' patience with regard to future profits.

We consider subgame perfect equilibria and restrict our attention to symmetric markovian strategies. Markovian strategies do not depend on time and in the subsequent analysis we omit the time superscript whenever possible. A strategy for bidder $i$ is a function of bidder $i$ 's cost, the contract's characteristics, and her own and her competitors' states, $b\left(c_{i}, s_{0}, s_{i}, s_{-i}\right)$. Let $\mathbf{b}_{-\mathbf{i}}$ denote a strategy profile of other bidders. We assume that the strategy profile $\mathbf{b}_{-\mathbf{i}}$ is such that the distribution of the low bid submitted by other bidders is continuous.

Payoff of a regular bidder: The discounted sum of future expected payoffs for bidder $i$ can be written in value function form as:

$$
\begin{aligned}
W_{i}\left(s, s_{0}, c_{i}, \mathbf{b}_{-\mathbf{i}}\right)= & \max _{b}\left[b-c_{i}\right] \operatorname{Pr}\left(i \text { wins } \mid b, s_{0}, s_{i}, s_{-i}, \mathbf{b}_{-\mathbf{i}}\right)+ \\
& +\beta \sum_{j=0}^{n_{F}} \operatorname{Pr}\left(j \text { wins } \mid b, s_{0}, s_{i}, s_{-i}, \mathbf{b}_{-\mathbf{i}}\right) E_{0} \int W_{i}\left(\omega\left(s_{0}, s, j\right), s_{0}^{\prime}, c_{i}^{\prime}, \mathbf{b}_{-\mathbf{i}}\right) \\
& \cdot f\left(c_{i}^{\prime} \mid s_{0}^{\prime}, \omega_{i}\left(s_{0}, s, j\right), \omega_{-i}\left(s_{0}, s, j\right)\right) d c_{i}^{\prime},
\end{aligned}
$$

where $\operatorname{Pr}\left(i\right.$ wins $\left.\mid b, s_{0}, s_{i}, s_{-i}, \mathbf{b}_{-\mathbf{i}}\right)$ denotes the probability that bidder $i$ with state $s_{i}$ wins contract $s_{0}$ given the strategy $\mathbf{b}_{-\mathbf{i}}$ by other bidders and the state $s_{-i}$ by other bidders; $E_{0}$ denotes the expectation operator with respect to the contract characteristic $s_{0}^{\prime}$; and, $j=0$ indicates that nobody won the auction. Notice, that due to the reserve price rule, any bid exceeding the reserve price will be rejected. Therefore, without loss of generality, we can assume that bids exceeding the reserve price equal $b_{0}$, with $b_{0}>\max \left(R^{t}\right)$, and restrict attention to the compact bid space $\left[0, \max \left(R^{t}\right)\right] \cup b_{0}$.

Existence of $W_{i}\left(s, s_{0}, c_{i}, \mathbf{b}_{-\mathbf{i}}\right)$ follows from a result in Bhattacharya and Majumdar (1989). To see this, notice that our assumptions imply that the period payoff function, $\left[b-c_{i}\right] \operatorname{Pr}\left(i\right.$ wins $\left.\mid b, s_{0}, s_{i}, s_{-i}, \mathbf{b}_{-\mathbf{i}}\right)$, is continuous in $b, c_{i}, s_{0}, s_{i}$ and $s_{-i}$, and bounded by 
the maximum reserve price $\max \left(R^{t}\right)$. Moreover, the bid space, $\left[0, \max \left(R^{t}\right)\right] \cup b_{0}$, is compact; the state space, $S$, and the contract space, $S_{0}$, are finite; and the cost space $[\underline{C}, \bar{C}]$ is compact. Furthermore, since $\operatorname{Pr}\left(j\right.$ wins $\left.\mid b, s_{0}, s_{i}, s_{-i}, \mathbf{b}_{-\mathbf{i}}\right)$ is continuous in $b, s_{0}, s_{i}$ and $s_{-i}$ for all $j$, it follows that the transition probability $\omega\left(s_{0}, s, j\right) \cdot \operatorname{Pr}\left(j\right.$ wins $\left.\mid b, s_{0}, s_{i}, s_{-i}, \mathbf{b}_{-\mathbf{i}}\right)$ is weakly continuous in $b, s_{0}, s_{i}$ and $s_{-i} \cdot{ }^{10}$ Finally, since the state space is finite, $F\left(. \mid s_{0}, s_{i}, s_{-i}\right)$ is weakly continuous in $s_{0}, s_{i}$ and $s_{-i}$. Thus, the infinite-horizon dynamic programming problem of bidder $i$ satisfies the necessary conditions of Theorem 3.2. in Bhattacharya and Majumdar (1989), which guarantees the existence of a unique solution to the value function, $W_{i}\left(s, s_{0}, c_{i}, \mathbf{b}_{-\mathbf{i}}\right)$.

In the subsequent analysis, we sometimes use the ex ante value function which is defined as the value function evaluated before contract characteristics and bidder $i$ 's cost are known. We can write the ex ante value function as:

$$
V_{i}\left(s, \mathbf{b}_{-\mathbf{i}}\right)=E_{0} \int W_{i}\left(s, s_{0}, c, \mathbf{b}_{-\mathbf{i}}\right) f\left(c \mid s_{0}, s\right) d c,
$$

where $E_{0}$ denotes the expectation operator with respect to contract characteristics. For the simplicity of the exposition, from now on we suppress the dependence on the bidding strategies of other bidders in the value function. The above value function equation leads to the following recursive equation for $V_{i}(s)$ :

$$
\begin{aligned}
V_{i}(s)= & E_{0}\left[\int \operatorname { m a x } _ { b } \left\{[b-c] \operatorname{Pr}\left(i \text { wins } \mid b, s_{0}, s_{i}, s_{-i}\right)+\right.\right. \\
& \left.\left.\beta \sum_{j=0}^{n_{F}} \operatorname{Pr}\left(j \operatorname{wins} \mid b, s_{0}, s_{i}, s_{-i}\right) V_{i}\left(\omega\left(s_{0}, s, j\right)\right)\right\} f\left(c \mid s_{0}, s_{i}, s_{-i}\right) d c\right] .
\end{aligned}
$$

Payoff of a fringe bidder: For a fringe bidder, the ex ante payoff equals to the expected current

\footnotetext{
10 If $D$ is a metric space, then $\mathcal{P}(D)$ denotes the set of all probability measures on the Borel sigmafield $\mathcal{B}(D)$ of $D$. A function $F$ on a metric space $D_{1}$ into $\mathcal{P}(D)$ is weakly continuous if the sequence of probability measures $F\left(y_{n}\right)$ converge weakly to $F(y)$ when $y_{n} \longrightarrow y$ in $D_{1}$.
} 
period payoff:

$$
E_{0}\left[\int \max _{b}\left\{[b-c] \operatorname{Pr}\left(i \text { fringe wins } \mid b, s_{0}, s\right)\right\} f_{f}\left(c \mid s_{0}, s\right) d c\right] \text {. }
$$

The role of our earlier assumptions on the behavior of fringe bidders can be illustrated at this point: Fringe bidders exit in the period they entered and, therefore, they assign no value to the future. The assumption that the cost of fringe bidders is contained in the interval $\left[\underline{C}, R^{t}\right]$ guarantees that fringe bidders find it profitable to submit a bid in the period they enter. In contrast, note that our model implies that a regular bidder may not submit a bid in a given period. This may arise either because the cost realization is above the reserve price, or because the cost of being constrained in the future outweighs the current period gain of winning the contract.

Existence of an equilibrium: We restrict attention to monotone and symmetric strategies $b\left(c, s_{0}, s_{i}, s_{-i}\right)$. Existence of an equilibrium follows from recent results on equilibrium existence in static asymmetric first price auctions by Lebrun (1996), Maskin and Riley (2000), Athey (2001) and others. Maskin and Riley consider payoff functions of the form $U_{i}(b, c) \cdot \operatorname{Pr}($ bidder $i$ wins). In our model the payoff in period $t$ to bidder $i$ with contract realization $s_{0}$, state vector $s$ and cost $c$ can be written as $U_{i}(b, c)=\left[b-c+\beta V_{i}\left(\omega\left(s_{0}, s, i\right)\right)+\right.$ $\left.\beta \sum_{j \neq i} \frac{\operatorname{Pr}\left(j \text { wins } \mid b, s_{0}, s_{i}, s_{-i}\right)}{\operatorname{Pr}\left(i \text { wins } \mid b, s_{0}, s_{i}, s_{-i}\right)} V_{i}\left(\omega\left(s_{0}, s, j\right)\right)\right] \cdot \operatorname{Pr}\left(i\right.$ wins $\left.\mid b, s_{0}, s_{i}, s_{-i}\right)+$ constant, which is of the same form as in Maskin and Riley. Proposition 5 in Maskin and Riley states that - at a given period $t$ of any first price auction game - an equilibrium exists if preferences are monotone, $\frac{\partial U_{i}}{\partial c}<0$, and supermodular, $\frac{\partial^{2} U_{i}}{\partial c \partial b} \leq 0$. These two conditions are satisfied in our model for any state $s$ and for any continuation value $V_{i}(s)$. Therefore, we can select one equilibrium strategy profile for every state vector $\left(s_{0}, s\right)$. The resulting strategy profile is markovian and by construction it is an equilibrium in the repeated game. ${ }^{11}$

\footnotetext{
11 Additionally, Proposition 3 in Maskin and Riley establishes that the distribution of winning bids is continuous. Thus, our earlier restriction to consider continuous distribution function of low competitors' bids does not affect the existence question.
} 
Bid distribution function: We denote the distribution function of equilibrium bids of bidder $i$ with state $\left(s_{0}, s_{i}, s_{-i}\right)$ by $G\left(. \mid s_{0}, s_{i}, s_{-i}\right)$, and the associated density by $g\left(. \mid s_{0}, s_{i}, s_{-i}\right)$. We denote the distribution function of equilibrium bids by a fringe bidder with state $\left(s_{0}, s\right)$ by $G_{f}\left(. \mid s_{0}, s\right)$ and the associated density function by $g_{f}\left(. \mid s_{0}, s\right)$. We sometimes suppress the $f$ subscript in the distribution function of fringe bids and instead write $G\left(. \mid s_{0}, s\right)$ to economize on notation. Doing so, the probability $\operatorname{Pr}\left(i\right.$ wins $\left.\mid b, s_{0}, s_{i}, s_{-i}\right)$ can be written as $\prod_{j \neq i}[1-$ $\left.G\left(b \mid s_{0}, s_{j}, s_{-j}\right)\right]$. The ex-ante probability distribution function of the event that bidder $i$ wins with a bid less than or equal to $b$ is denoted by $G^{(i)}\left(b \mid s_{0}, s\right)$, and the probability density function associated with $G^{(i)}\left(b \mid s_{0}, s\right)$ is given by $\prod_{j \neq i}\left[1-G\left(b \mid s_{0}, s_{j}, s_{-j}\right)\right] g\left(b \mid s_{0}, s_{i}, s_{-i}\right)$.

\section{ESTIMATION METHOD}

This section describes the estimation method: Subsection 3.1. explains the estimation approach which is based on the first order condition of optimally chosen bids. The first order condition provides an explicit function of the cost in terms of the submitted bid, the distribution of bids, and the value function. We show that the value function, which enters the first order condition, can be represented in form of a recursive equation involving the equilibrium bid distribution function. Therefore, with an estimate of the bid distribution function we can infer costs using the first order condition of optimal bids. Subsection 3.2 establishes a condition under which the distribution function of privately known costs is identified. Subsection 3.3 describes in detail our parametric specification of the bid distribution function.

\subsection{ESTIMATION APPROACH}

We observe data on bids, contract characteristics and bidders' state variables. Our goal is to infer privately known costs. We propose a computationally simple estimation method that does not require solving for the equilibrium bid functions. The method is based on the necessary first order condition of optimal bids and requires the assumption that observed bids are generated by equilibrium play.

Estimation methods based on the first order condition in static games are well known in the literature. Elyakime, Laffont, Loisel and Vuong (1994) estimate the beliefs about the 
equilibrium play of agents based on data on bids. The cost realization is then inferred from the first order condition. We extend the estimation method to dynamic oligopoly models.

First order condition: Let $\phi($.$) denote the unobserved cost associated with a bid, which$ is a function of the bid, $b$, the contract characteristics, $s_{0}$, the state vector, $s$, and the value function $V_{i}$. Let $h\left(. \mid s_{0}, s_{i}, s_{-i}\right)=\frac{g\left(. \mid s_{0}, s_{i}, s_{-i}\right)}{1-G\left(. \mid s_{0}, s_{i}, s_{-i}\right)}$ denote the hazard function of bids submitted by bidder $i$ when the state equals $\left(s_{0}, s_{i}, s_{-i}\right)$. The first order condition for optimal bids yields the following equation (see the Appendix for a more detailed description) for privately known costs, $\phi$ :

$$
\begin{aligned}
\phi\left(b \mid s_{0}, s_{i}, s_{-i}, h, V_{i}\right) & =b-\frac{1}{\sum_{j \neq i} h\left(b \mid s_{0}, s_{j}, s_{-j}\right)}+ \\
& +\beta \sum_{j \neq i} \frac{h\left(b \mid s_{0}, s_{j}, s_{-j}\right)}{\sum_{l \neq i} h\left(b \mid s_{0}, s_{l}, s_{-l}\right)}\left[V_{i}\left(\omega\left(s_{0}, s, i\right)\right)-V_{i}\left(\omega\left(s_{0}, s, j\right)\right)\right] .
\end{aligned}
$$

Equation (3.2.) provides an explicit expression of the privately known cost that involves the bid; the hazard function of bids, $h$; and, the value function, $V_{i}$. Equation (3.2.) states that the cost equals the bid minus a mark-down. The mark-down has two parts: The first part accounts for the level of competition in the current period. The second part accounts for the incremental effect on the future discounted profit if firm $i$ wins the contract instead of another firm. The first order condition for fringe bids is of the same form as equation (3.2.). However, fringe bidders assign no value to the future, $V_{f}=0$, and the second term in equation (3.2.) vanishes for fringe bids.

The first order condition provides an explicit function of the cost for a submitted bid, $b \leq R$. If a bid is not submitted, $b>R$, then the monotone relationship (3.2.) implies a lower bound for the cost, $c \geq \phi\left(R \mid s_{0}, s_{i}, s_{-i}, h, V_{i}\right)$.

In order to infer the distribution of costs, we need estimators for the functions appearing in the right hand side of (3.2.). These functions are: The transition function of the state, the bid hazard function, the discount factor, and the value function. As described before, in our auction model, the transition function of the state is a given function. An estimator of the bid 
distribution function, and thus of the hazard function, can be directly obtained from the data on bids, contract characteristics and state variables. We describe the details of our estimator in section 3.3. The discount factor we choose - and we examine how sensitive the estimates are to variations in the discount factor. Finally, the definition of the value function is given in equation (3.1.). However, observe that the expression of the value function in equation (3.1.) involves cost variables that are unobserved, and decisions by multiple agents, which are endogenous. In the next paragraphs, we explain how we overcome the problems posed by this latter observation and obtain an approximation of the value function.

The Value Function: The key idea of our method is to notice and use the fact that the distribution of equilibrium bids determines the discounted sum of expected future profits. Thus, there is a representation of the value function in terms of the distribution of bids only. The following Proposition states that the value function can be represented as a recursive equation involving the bid distribution function. The proof of Proposition 1 is given in the Appendix.

\section{Proposition 1.}

$$
\begin{gathered}
V_{i}(s)=E_{0}\left\{\int_{\underline{b}}^{R} \frac{1}{\sum_{j \neq i} h\left(. \mid s_{0}, s_{j}, s_{-j}\right)} d G^{(i)}\left(. \mid s_{0}, s\right)+\beta \sum_{j=0, j \neq i}^{n_{F}}\left[\operatorname{Pr}\left(j \text { wins } \mid s_{0}, s_{i}, s_{-i}\right)\right.\right. \\
\left.\left.\quad+\int_{\underline{b}}^{R} \frac{h\left(. \mid s_{0}, s_{i}, s_{-i}\right)}{\sum_{l \neq i} h\left(. \mid s_{0}, s_{l}, s_{-l}\right)} d G^{(j)}\left(. \mid s_{0}, s\right)\right] \cdot V_{i}\left(\omega\left(s_{0}, s, j\right)\right)\right\} .
\end{gathered}
$$

The value function representation in Proposition 1 has two parts: The first part accounts for bidder $i$ 's current expected profits. The second part accounts for bidder $i$ 's sum of discounted expected future payoffs. Notice that the terms in square brackets in (3.3) can be interpreted as probabilities, as they sum to one, since $\operatorname{Pr}\left(i\right.$ wins $\left.\mid s_{0}, s_{i}, s_{-i}\right)=$ $\sum_{j \neq i} \int_{\underline{b}}^{R} \frac{h\left(. \mid s_{0}, s_{i}, s_{-i}\right)}{\sum_{l \neq i} h\left(. \mid s_{0}, s_{l}, s_{-l}\right)} d G^{(j)}\left(. \mid s_{0}, s\right)$.

The proof of the Proposition is based on two observations: First, we may write the probability of winning as a function of the distribution of bids by other bidders, ignoring 
dependence of other bidders' bids on costs' draws. Thus, each bidder dynamic game is reduced to a single agent dynamic decision problem where each bidder maximizes the discounted sum of future payoffs taking as given the equilibrium bid distribution associated with other bidders. Still, this single agent dynamic decision problem does involve bidder $i$ 's privately known costs which are not observed. Our second observation is that the first order condition of optimal bids gives an explicit expression of bidder $i$ 's unknown costs in terms of her equilibrium bids and the equilibrium bids distribution. Substituting this expression into the value function yields an expression involving the distribution and the density of equilibrium bids only.

Approximation of the Value Function: Numerical methods can be used to approximate the value function based on equation (3.3.), which we describe next. The assumption of a symmetric markovian strategy space imposes a number of restrictions on the shape of the value function which facilitates the approximation. In particular, Pakes (1994) shows that the number of coefficients in a $J$ th order polynomial approximation does not increase as the number of bidders increases. The reason is that symmetric markovian strategies require that bidders with the same state follow the same bidding strategy. Thus, we can exchange the state of two competing bidders without affecting the value of bidder $i$ 's expected future payoffs. As has been shown by Pakes, in a $J$ th order polynomial approximation of the value function, the polynomial coefficients associated with the state variable of a competitor $j, s_{j}$, are identical for all $j \neq i$, or, in other words, their identities do not matter. In section 5, we discuss in detail the variables entering the value function approximation. In our case, the dimensionality of the approximation is reduced to a four dimensional problem for each bidder.

Numerical methods to approximate the value function based on equation (3.3.) are discussed in more detail in Judd (1998). We briefly summarize the method we use: We select a grid of state vectors $\hat{S}=\left(s^{1}, \ldots, s^{m}\right)$ by randomly drawing 200 states from the distribution of observed states. We numerically solve equation (3.3.) for every bidder on this grid. We restrict the range of the transition function $\omega$ to $\hat{S}$ by defining a transition function $\hat{\omega}\left(s_{0}, s, j\right)=\left\{s \in \hat{S} \mid s\right.$ is closest to $\left.\omega\left(s_{0}, s, j\right)\right\}$. For every point $s \in \hat{S}$ we calculate the expectations on the right hand side of equation (3.3.). Specifically, we numerically evaluate 
the expected current period payoff,

$$
A(s)=E_{0}\left\{\int \frac{1}{\sum_{j \neq i} h\left(. \mid s_{0}, s_{j}, s_{-j}\right)} d G^{(i)}\left(. \mid s_{0}, s\right)\right\},
$$

and the transition probabilities of the events that the states $\left(s^{1}, \ldots, s^{m}\right)$ are reached when bidder $j$ wins the contract,

$$
B_{j}(s)=E_{0}\left\{\int\left[1+\frac{h\left(. \mid s_{0}, s_{i}, s_{-i}\right)}{\sum_{l \neq i} h\left(. \mid s_{0}, s_{l}, s_{-l}\right)}\right] d G^{(j)}\left(. \mid s_{0}, s\right) \cdot\left(1_{\left\{\hat{\omega}\left(s_{0}, s, j\right)=s^{1}\right\}}, \ldots, 1_{\left\{\hat{\omega}\left(s_{0}, s, j\right)=s^{m}\right\}}\right)\right\} .
$$

In both expressions, the first expectation is with respect to contract characteristics. We evaluate the expectation with respect to contract characteristics in the following way: We select a set of contract characteristics, $\hat{S}_{0}$, by randomly drawing 100 contracts from the set of observed contracts. Contract characteristics' are modeled as independent and identical draws from the set $\hat{S}_{0}$. The second expectation depends on the bid distribution function. The specification of the bid distribution function is described in the next section. We evaluate the expectation with respect to the bid distribution function by numerical integration using the estimated density functions $d \hat{G}^{(i)}$ and $d \hat{G}^{(j)}$. Using the symbol $A$ for current period payoff and $B_{j}$ for the transition probabilities, the value function is given by the equation,

$$
V_{i}(s)=A(s)+\beta \sum B_{j}(s) V_{i}
$$

where $V_{i}$ denotes the vector $\left(V_{i}\left(s^{1}\right), \ldots, V_{i}\left(s^{m}\right)\right)^{\prime}$. We can rewrite the value function in matrix notation as: $[I-\beta B] V_{i}=A$, where $I$ denotes the $m$-dimensional identity matrix, $B$ denotes the transition matrix obtained based on the coefficients $B_{j}(s)$ and $A$ denotes the vector $\left(A\left(s^{1}\right), \ldots, A\left(s^{m}\right)\right)$. The value function can be expressed as:

$$
V_{i}=[I-\beta B]^{-1} A
$$

To evaluate the value function for points $s \in \mathcal{S}$, possibly outside the grid $\hat{S}$, we approximate the function with a quadratic polynomial. 
Estimation of the cost distribution function: With the distribution function of bids at hand, the parameters of the bidding model can be readily inferred. To see how we infer the distribution of costs, notice the following: First, there is a relationship between the distribution function of costs and the distribution function of bids given by $F\left(c \mid s_{0}, s_{i}, s_{-i}\right)=$ $G\left(b\left(c, s_{0}, s_{i}, s_{-i}\right) \mid s_{0}, s_{i}, s_{-i}\right)$. Second, the inverse of the bid function conditional on state variables, $c=\phi\left(b \mid s_{0}, s_{i}, s_{-i}\right)$, is given in equation (3.2.). Thus, using these two relationships, we can specify our estimator of the costs' distribution function as:

$$
F\left(c \mid s_{0}, s_{i}, s_{-i}\right)=G\left(\phi^{-1}\left(c \mid s_{0}, s_{i}, s_{-i}\right) \mid s_{0}, s_{i}, s_{-i}\right),
$$

for $c \leq \phi\left(R\left(s_{0}\right) \mid s_{0}, s_{i}, s_{-i}\right)$. Standard errors of estimates are calculated using the delta method.

A nice feature of the auction model is that the discount factor and the distribution of costs are the only unknown parameters in the model. However, observe that our estimation method extends to models in which the per period payoff function may depend on additional parameters. For example the Hotz and Miller (1993) estimator can be applied..$^{12}$

Next, we examine whether the distribution function of costs can be identified.

\subsection{IDENTIFICATION}

This subsection addresses the question of under which conditions we can infer the parameters of our model. There are two related and somewhat opposing results in the literature: Guerre, Perrigne and Vuong (2000) have established that, in the static first price auction, the distribution of costs is identified. On the other hand, Rust (1994) finds that the primitives in a dynamic decision problem with an unknown per-period payoff function are not identified. Proposition 2 establishes that our model lies in between those two extremes. First, observe that, in our setting, the identification problem consists in determining if the two underlying primitives, which are the distribution of $\operatorname{costs} F(. \mid$.) and the discount factor $\beta$, are identified based on expressions (3.1.) and (3.2.), and a sufficient number of observations $\left(b^{t}, s_{0}^{t}, s^{t}\right)$.

12 Hotz and Miller define an iterative procedure for single agent dynamic decision problems in which the value function is calculated for a given parameter vector at every step of the iteration. A method of moments estimator is defined which compares the predicted and observed actions based on the first order condition. Although Hotz and Miller consider discrete choices, it can also be applied to continuous choices. 
Proposition 2. Suppose $\beta$ is given. Then the cost distribution function $F(. \mid$.$) is iden-$ tified on the interval $[\underline{C}(),. \phi(R() \mid)$.$] .$

The Proposition establishes that the truncated distribution of costs is identified for a fixed discount factor $\beta$. The truncation occurs at the point where it is not profitable to submit a bid, that is for costs exceeding $\phi\left(R\left(s_{0}\right) \mid s_{0}, s_{i}, s_{-i}\right)$. Thus, in contrast to Rust (1994) we obtain a partially positive answer in our model. A main reason for the apparently opposing result is that the reward function is known in our auction model, but not known in Rust. As in Rust (1994), the discount factor is not identified and the condition in the Proposition is necessary. To see this, notice that there can be two discount factors $\beta_{1}, \beta_{2}$, with $\beta_{1} \neq \beta_{2}$, and associated distribution functions $F_{1}, F_{2}$, with $F_{1} \neq F_{2}$, such that $\left(\beta_{1}, F_{1}\right)$ and $\left(\beta_{2}, F_{2}\right)$ lead to the same distribution function $G(. \mid$.$) .$

\subsection{BID DISTRIBUTION FUNCTIONS}

So far we have described the estimation procedure to infer costs and addressed the identification question. Thus, what is left to do is to specify our estimator of the distribution function of bids. This section describes the parametric specification of the bid distribution function of fringe and regular bidders. In addition, we discuss the restrictions on parameters implied by the bidding model and describe how we impose these restrictions on the estimation procedure.

At an early stage of the research, we adopted Kernel methods to estimate the bid distribution functions as is proposed by Guerre, Perrigne and Vuong (2000). Our estimation results are summarized in Jofre-Bonet and Pesendorfer (2000). In this earlier work, we found that non-parametric approaches reduce greatly the number of covariates we could use, which, in our case, limited severely the ability of the model to capture the richness of the data. For this reason we decided to adopt a parametric framework.

The bid distribution function is not a primitive of the model. However, Jofre-Bonet and Pesendorfer (1999) provide the equilibrium mapping from costs into bids for a particular class of cost distribution functions. In this paper, we select a parametrization of the bid distribution function of regular bidders that contains that particular class of costs distribution functions as 
a special case. In other words, the example in Jofre-Bonet and Pesendorfer (1999) illustrates a class of cost distribution functions that satisfies our parametric assumptions.

Density function of regular bidders: We experimented with different specifications for the density function of bids by regular bidders and we obtained the best fit with a Weibull density function. Specifically, we define the density function of the logarithm of bids by regular bidder $i$ plus one, $\ln (b+1)$, as a Weibull density function. The lower endpoint of the Weibull density function is $\ln \left(\theta_{3}+1\right)$. In our specification, the parameters of the density are a function of the state variables and contract characteristics. By suppressing the parameters' dependence on these variables, we can write the density function as:

$$
g\left(b \mid \theta_{1}, \theta_{2}, \theta_{3}\right)=\left[\frac{\theta_{1}\left[\ln (b+1)-\ln \left(\theta_{3}+1\right)\right]^{\theta_{1}-1}}{\theta_{2}^{\theta_{1}}}\right] \exp ^{-\left(\frac{\ln (b+1)-\ln \left(\theta_{3}+1\right)}{\theta_{2}}\right)^{\theta_{1}}} .
$$

The support of bids for regular bidders is $\left[\theta_{3}, \infty\right) .{ }^{13}$ The parameters of the distribution function consist of the constant $\theta_{1}$, and two parameters, $\theta_{2}$ and $\theta_{3}$, that depend on the state variables as will be explained below.

The density function of bids by fringe bidders is specified as a beta density function. We can write the density function as:

$$
g_{f}\left(b \mid \theta_{3}, \theta_{4}, \theta_{5}\right)=\frac{1}{R-\theta_{3}}\left(\frac{b-\theta_{3}}{R-\theta_{3}}\right)^{\theta_{4}-1}\left(\frac{R-b}{R-\theta_{3}}\right)^{\theta_{5}-1} \frac{1}{B\left(\theta_{4}, \theta_{5}\right)},
$$

where the distributional parameter $\theta_{4}$ is a constant; the distributional parameters, $\theta_{3}, \theta_{5}$, depend on the state variables as will be described below; $R$ denotes the reserve price; the support of fringe bids is $\left[\theta_{3}, R\right]$; and, the function $B\left(\theta_{4}, \theta_{5}\right)$ denotes the beta function. ${ }^{14}$

Estimation procedure: The regularity conditions of maximum likelihood need not hold for auction models as has been shown by Donald and Paarsch (1993). In our case a non-regularity arises since one parameter is the boundary of the support of bids. There is a substantial statistics literature including Smith (1985), Harter and Moore (1965) and Smith (1994) studying

13 In principle, it is possible to estimate different supports of bid distributions for individual bidders. However, we restrict the supports to be identical. The main reason is that, empirically, with a small data sample, it is difficult to determine whether bidders have indeed different supports or not.

$$
14 \quad B(v, w)=\int_{0}^{1} u^{v-1}(1-u)^{w-1} d u .
$$


properties of estimation methods of the support and shape parameters for the Weibull and beta distribution function. Smith (1985) shows that the maximum likelihood estimates of the parameters are consistent and efficient provided that $\theta_{1}, \theta_{4} \geq 2 .{ }^{15}$ For the case $\theta_{1}, \theta_{4}<2$ Harter and Moore (1965), Smith (1985)and Smith (1994) describe a two stage estimation procedure: In the first stage the lower bound is estimated using the sample minimum. In the second stage the observation involving the sample minimum is dropped and the shape and scale parameters are estimated using maximum likelihood. Smith (1994) considers a multi-dimensional lower bound and proposes a linear program estimator for the lower bound to be used in the first stage. Smith (1985) and Smith (1994) establish that the two stage estimation procedure is consistent for $\theta_{1}, \theta_{4}>1$, and also asymptotically efficient, provided the density does not vanish too fast at the lower bound, $1 \leq \theta_{1}, \theta_{4}<2$. The above results require that $\theta_{1}$ and $\theta_{4}$ are one dimensional, and allow $\theta_{2}, \theta_{3}$ and $\theta_{5}$ to be multi-dimensional. The asymptotic results do not readily extend to the case in which $\theta_{1}$ and $\theta_{4}$ are multi-dimensional.

We estimate the model using both estimation procedures. Under the two stage estimation procedure, we found that $\theta_{1}$ and $\theta_{4}$ exceed 2. Therefore, only maximum likelihood is efficient. In the following sections, we report the estimation results using maximum likelihood estimation.

Restrictions on the parameters: As mentioned, some of the distributional parameters are a function of state variables and contract characteristics. Nevertheless, there are a number of restrictions on the functional form of the parameters' dependence on the state variables. First, there are the restrictions that $\theta_{2}, \theta_{5}>0$, and that $\theta_{1}, \theta_{4} \geq 2$. These restrictions ensure that the conditions for a probability density function are satisfied, that the monotonicity of the bid hazard functions holds, which is required from the bidding model, ${ }^{16}$ and that we can apply the asymptotic efficiency result in Smith (1985). Moreover, we assume that bids are non-negative. To impose these restrictions, we define $\theta_{j}=2+\exp ^{\theta_{0 j}}$ for $j=1,4$, and $\theta_{j}=\exp ^{\theta_{0 j}}$ for $j=2,3,5$.

\footnotetext{
15 For $\theta_{1}, \theta_{4}<1$, the maximum likelihood estimators may be inconsistent.

16 For $\theta_{1}, \theta_{4}<1$, the hazard of bids can be decreasing, which would violate the condition that equilibrium bids are monotone increasing in costs.
} 
The second restriction is the symmetry of the bidding functions conditional on state variables. Bidders with the same state follow the same bidding strategy. Thus, the parameter entering the bid distribution of fringe firms, $\theta_{03}(s), \theta_{05}(s)$, should not be affected by the order of elements in the vector $s$. Similarly, the order of elements in the vector $s_{-i}$ does not matter for parameter $\theta_{02}$ either. We consider the following specification which incorporates the described conditional symmetry restrictions:

$$
\begin{array}{cr}
\theta_{0 j}\left(s_{0}, s_{i}, s_{-i}\right)=\gamma_{j, 0}+\gamma_{j, 1} s_{0}+\gamma_{j, 2} \Psi\left(s_{i}, s_{0}\right)+\gamma_{j, 3} \cdot \sum_{l=1}^{n} \Psi\left(s_{l}, s_{0}\right) & \text { for } j=2 \\
\theta_{0 j}\left(s_{0}, s\right)=\gamma_{j, 0}+\gamma_{j, 1} s_{0}+\gamma_{j, 2} \cdot \sum_{l=1}^{n} \Psi\left(s_{l}, s_{0}\right) & \text { for } j=3,5,
\end{array}
$$

where $\Psi\left(s_{i}, s_{0}\right)$ is a function that denotes the characteristics of a bidder with state $s_{i}$ on contract $s_{0}$. The function $\Psi\left(s_{i}, s_{0}\right)$ captures the possibility that bidder characteristics may vary across contracts.

Likelihood function: Finally, in order to estimate the density functions described above, we have to take into account that the bid data for regular bidders are censored. We only observe bids that are below the reserve price, $R^{t}$. Let $o_{i}^{t}$ be a dummy variable that equals one if we observe a bid by bidder $i$ on contract $t$, and zero otherwise. In an abuse of notation, we abbreviate the dependence of parameters on the state vector with superscripts, and write the parameter vector for regular bidders as $\theta^{i t}$ where $\theta^{i t}=\left(\theta_{1}, \theta_{2}\left(s_{0}^{t}, s_{i}^{t}, s_{-i}^{t}\right), \theta_{3}\left(s_{0}^{t}, s^{t}\right)\right)$. Similarly, the parameter vector for fringe bidders we abbreviate as $\theta^{t}$ where $\theta^{t}$ denotes $\left(\theta_{3}\left(s_{0}^{t}, s^{t}\right), \theta_{4}, \theta_{5}\left(s_{0}^{t}, s^{t}\right)\right)$. Doing so, we may write the likelihood of regular and fringe bids as:

$$
L=\prod_{t}\left[\prod_{i=1}^{n}\left[g\left(b_{i}^{t} \mid \theta^{i t}\right)\right]^{o_{i}^{t}}\left[1-G\left(R^{t} \mid \theta^{i t}\right)\right]^{1-o_{i}^{t}} \prod_{j=n+1}^{n_{F}^{t}} g_{f}\left(b_{j}^{t} \mid \theta^{t}\right)\right],
$$

where $b_{i}^{t}$ is the bid by regular bidder $i$ on contract $t$, and $b_{j}^{t}$ is the bid by fringe bidder $j$ on contract $t$. We assume that the initial state $s^{1}$ is exogenous. We maximize the logarithm of 
the likelihood function. Billingsley (1961) establishes the asymptotic properties of maximum likelihood estimators for Markov processes, as the number of auctions $T$ goes to infinity. The Markovian structure of the observed controlled process $\left(s_{0}, s, b\right)$ follows directly from the assumption that the cost realizations are conditionally independently distributed, the bid functions are Markovian, and the assumption that the distribution of contract characteristics is exogenous. A closely related result is Theorem 3.3 in Rust (1994).

The next section describes the data and the industry. Section 5 reports the estimation results.

\section{THE DATA AND INDUSTRY}

In this section, we describe some characteristics of the highway construction industry with emphasis on California. We present our data and describe the awarding process for contracts. In addition, we report reduced form evidence on the effect of previously won and uncompleted contracts on bid submission and bid level decisions.

\subsection{THE CALIFORNIA MARKET}

According to the 1992 US Census of Construction Industries ${ }^{17}$ a total of $\$ 35.3$ billion were spent during 1992 on highway and street construction activities. In California, the total amount spent in highway construction was $\$ 2.7$ billion, $93 \%$ of which was done by 896 establishments located in California. Transportation costs play an important role in this industry, and, therefore, we consider California as a market.

The data: Our data consist of California Department of Transportation (Caltrans) contract awards for highway and street construction made between December 1988 and May 1999. ${ }^{18}$ Information on bids is available from May 1st, 1996 through May 31st, 1999. During the latter period, Caltrans advertised 2,566 projects from which 2,207 were finally awarded,

17 U.S. Department of Commerce, Economics and Statistics Administration, Bureau of Census, 1992.

18 We obtained our data from the California Department of Transportation. The Office of Engineers publishes the data on the web: http : //www.dot.ca.gov/hq/esc/oe/awards/bidsum. 
343 cancelled or postponed ${ }^{19}$ and 16 received no bids.

The bid data contain the following information on every project awarded: Bid Opening Date; Contract Number; Location; Reservation Price; Number of Working Days and the Engineers' Estimate. Additionally, the data provides the Name, the Address, the Amount of the Bid and the Rank of the Bid for each of the bidding firms. In order to obtain a measure of past performance and maximum capacity of the firms active in our period of analysis, we complement the bid data with the Caltrans Contract Performance database. This source contains information on contracts awarded between December 1988 to May 1999. It provides the actual dollar amount received for the contract, the contract duration and the identity of the contractor.

The Awarding Process: Contracts are awarded by the California Department of Transportation subject to Federal Acquisition Regulations and, therefore, is very similar to other states' procedures. The process can be described in three steps: First, the Caltrans' Headquarters Office Engineer announces a project that is going to be let and the invitation to submit bids starts. This period is called the Advertising period and its length ranges between 4 and 10 weeks, depending on the size or complexity of the project. Occasionally, the Advertising period will be reduced to expedite project scheduling. Second, potential bidders may collect bid proposals that explain the plans and specifications of the work required, i.e., the project's characteristics, terms and identification number. Based on the proposal, bidders may submit a sealed bid. Bidders do not know who else submits a bid. For each bid, Caltrans checks that the bidding firm is among the firms that are qualified to do business with Caltrans. ${ }^{20}$

19 According to the Federal Acquisition Regulation, part 14, a contract might be cancelled before opening if either the project is no longer needed or if the advertised contract characteristics become obsolete or inadequate and have to be revised. Other reasons to cancel are that all bids are either unreasonable or collusive or both. Cancellation can also occur if all reasonable bids belong to bidders that can not prove to be responsible. Additionally, the awarding agency might postpone the opening bids if it believes that a large fraction of bids have been delayed in the mail or other disruptive circumstances interfered in the regular reception of bids.

20 Prior to the bidding, potential bidders have to qualify for contractual work for the Department of Transportation. In addition, firms are required to deposit a predetermined amount of funds that have to be available. Receipt of funds clearance, permit issuance and local agencies approvals are needed for the bid of a firm to be accepted. A submitted bid can 
Third, on the letting day, the bids received are unsealed and ranked. The project is awarded to the lowest bidder provided it is below the reserve price. The reserve price consists of a fixed non-random dollar amount which is assigned prior to the bidding. Additionally, in order to win the project, it is required that the lowest bidder fulfills certain responsibility criteria. The bid is accepted if all computations and cost imputations are considered correct. After each letting, a list of all bids and their rankings is announced and made accessible to the public. The winning firm is awarded the project no more than 30 days after the letting date.

The highway paving industry has already been studied by a number of authors. Porter and Zona (1993) and Feinstein, Block and Nold (1985) study issues of bidder collusion. Bajari (1997) studies asymmetry between bidders. He estimates a static bidding model based on a numerical calculation of equilibrium bid functions.

\subsection{DESCRIPTIVE STATISTICS}

Between May 1st of 1996 and May 31st of 1999, the Caltrans awarded 2,207 contracts. The total value of the contracts was $\$ 4,661.73$ million.

Contracts are offered for sale on a frequent and regular basis. Typically, there are several letting dates per week. According to our data, the average duration between letting dates equals 2.96 days. Several contracts may be offered on a given letting date and contracts are offered in 11 distinct regions of the state.

(TABLE $1 \mathrm{~A}$ and TABLE $1 \mathrm{~B}$ about here)

Table $1 \mathrm{~A}$ reports that on average there were 4.63 bidders per contract, ranging from 0 to 19 bidders across contracts. A total of 10,289 bids were received for these contracts and 16 contracts received no bids. ${ }^{21}$ Table 1B reveals that a total of 96 contracts received one bid, 285 contracts received two, 393 contracts received three bidders and so on.

be rejected if either it fails to conform to the essential requirements of the invitation for bids; or does not conform to the applicable specifications without having been authorized to do so; or fails to conform to the delivery schedule or permissible alternates stated in the invitation.

21 A total of 1,466 submitted bids, or $12 \%$ of all bid observations, violate the reserve price requirements. We exclude these bids from the analysis. These bids may have been submitted erroneously. Alternatively, bidders may have expected that the reserve price rule would not be enforced. According to conversations with Caltrans, it is indeed possible that the reserve price is altered ex post. Nevertheless, our data do not include information on bids below the 
Table 1B illustrates that in highway procurement competition and informational asymmetries may be important. As the number of bidders increases, the relative difference between the low bid and the Caltrans estimate falls. The low bid is $11 \%$ above the estimate when there is one bidder, and the low bid falls to $14 \%$ below the estimate when there are nine or more bidders.

Money left on the table measures the difference between the low and second lowest bid. As expected, the difference declines as the number of bidders increases. However, it does not approach zero. When there are nine or more bidders, the money left on the table is about $6 \%$ of the low bid, which suggests that the magnitude of informational asymmetries may be quite large.

Fringe and regular bidders: In total, more than 500 bidders submit a bid at least once. Most of these bidders submit a bid only once, or only on a few occasions. For these bidders, the number of bid observations are too few to make inference about their behavior in a repeated game setting. We classify these bidders as fringe bidders. On the other hand, there is a small number of bidders that submit bids regularly and win a substantial fraction of contracts. With "regular" bidders we denote the set of the largest 10 firms in dollar value won that submit a bid at least 80 times during the sample period. ${ }^{22}$ The number of regular bidders per contract ranges from 0 to 4 and has an average of 0.53 . Regular bidders win $25 \%$ of the total dollar value awarded and $17 \%$ of all contracts. For these 10 regular bidders, we supplement the data with information on the locations of their plants. Then, for each firm, we create a variable called distance that measures the distance between the contract location and the firm's closest plant.

reserve price being rejected, or bids above the reserve price being accepted. The lack of data points that fall into either of these two categories, suggests that the probability of these events is low. In our analysis we assume that the reserve price rule is binding.

22 The estimation results and, in particular, the effect of backlog, remain very similar as we vary the definition of regular bidders. 


\subsection{THE EFFECT OF BACKLOG}

During our sample period, the average contract duration is 156 days. We define backlog as the amount of work measured in dollars that is left to do from previously won projects. The backlog variable is constructed in the following way: For every contract previously won, we calculate the amount of work measured in dollars that is left to do by taking the initial size of the contract and multiplying it by the fraction of time that is left until the project's completion date. For contracts that finished prior to the end of the sample period, we use the actual completion date of the contract. For contracts that did not finish by the end of the sample period, we use the planned completion date. Based on this calculation, we determine the total amount of work measured in dollars that is left to do at any given point in time. We standardize the backlog variable by subtracting the bidder specific mean (calculated using daily observations) and dividing this difference by the bidder specific standard deviation. The resulting backlog variable is a number that is comparable across bidders. ${ }^{23}$ There is substantial variation in the backlog variable. On average on about $10 \%$ of the observations a regular bidder has almost no capacity committed at the letting day, while on about $5 \%$ of the observations, the firm is about two standard deviations above its average backlog.

The effect of backlog in a simple dynamic bidding game is described in Jofre-Bonet and Pesendorfer (1999). Using a theoretical model, they examine the case in which bidders with above average backlog levels, or capacity constrained bidders, have a higher cost, in the sense of first order stochastic dominance, than unconstrained bidders. A prediction from the bidding model is that constrained bidders bid less frequently and higher than unconstrained bidders. Alternatively, there may be benefits to performing several contracts simultaneously which we may call expertise effect. Suppose the expertise effect lowers the cost of additional projects in the sense of first order stochastic dominance. In this latter case, a prediction of the bidding

23 We experimented with different definitions of the backlog variable. In particular, we also used a variable that measures the total backlog from previously won uncompleted contracts divided by the maximum dollar amount won during the sample period. The estimation results were very similar. We prefer the described specification because we do not have an accurate estimate of the maximum capacity. We also experimented with regional backlog variables. The regional effects appear less important perhaps because capacity and resources can be moved. Therefore, we report the results of the analysis when only the aggregate backlog level is used. 
model is that bidders with high backlog bid more frequently and lower than bidders with low backlog. Next, we assess the presence of these opposing intertemporal effects by using a reduced form analysis.

\section{(Table 2)}

Reduced form estimates: Table 2 reports nine columns of estimation results. The first three columns report Probit estimates of the decision to submit a bid. The fourth to sixth column report Tobit estimates of the bid level decision. The seventh to ninth column report Heckman estimates of the bid level decision. We observe bids only if they are below the reserve price. To apply the Tobit and Heckman analysis we consider a transformation of the bid. The dependent variable equals the reserve price minus the bid and is divided by the engineers' estimate. The dependent variable is negative if the bid is not observed, and it is positive if the bid is below the reserve price. Explanatory variables include contract specific characteristics, such as the estimate and the number of working days, and bidder specific characteristics such as the firm's size, measured as the number of plants in the region, the distance of the bidder's closest plant to the project location, and the bidder's backlog. For each regression, we report three sets of estimates: without any firm specific dummy variables, with a set of firm specific fixed effects, and with a set of firm specific backlog variables.

Backlog has a significant effect in all specifications. The sign of the coefficients suggests the presence of capacity constraints. The magnitude of the effect is substantial. An examination of the coefficients reveals that, on average, a constrained bidder is $50 \%$ less likely to submit a bid than an unconstrained bidder. An increase of the backlog from -1 to 1 increases the bid level between $2.5 \%$ and $7.6 \% .^{24}$

Asymmetries between bidders accounted for by observable variables are important. In addition to capacity effects, asymmetries between bidders due to location and size have significant effects. Distance to the project decreases the probability of submitting a bid and increases the bid level. The size of the bidder, measured by the number of plants within the region, increases the probability of submitting a bid. The effect of size on the bid level decision is

24 Note that if a firm's backlog changes from -1 to +1 , its committed capacity increases from one standard deviation below its average value to one standard deviation above it. 
negative in the Tobit model and not significant in the Heckman model.

Bidder heterogeneity not captured by our observables is also present. Firm specific fixed effects are included in columns two, five and eight. In all three specifications we can reject the null of no significant firm fixed effects. ${ }^{25}$ A possible explanation is that the paving technology between firms differs beyond what our measures of firm size, backlog and location capture. Ideally, we would like to have additional variables measuring firm heterogeneity.

Bidder heterogeneity not captured by our observables may account for part of the backlog effect, which could bias our estimates. We test whether the coefficient of the backlog variable changes as we introduce firm specific fixed effects. As is evident in the Table, the coefficients do not change significantly. Thus, excluding unobserved firm heterogeneity does not affect the estimates of the backlog effect.

As described in section 2, our model requires that bidders behave symmetrically conditional on observables. We can test this assumption by including a set of backlog and bidder identity interaction terms. We report these results in columns three, six and nine of Table 2. We find that the interaction terms are not significant for the majority of firms. An examination of individual coefficients reveals that 21 out of 27 coefficients are not significantly different from zero. Although we can reject the null of no significant firm specific backlog effects for all firms jointly in all three columns ${ }^{26}$, we cannot reject the null that firm specific backlog effects are zero for eight of the ten firms in all three specifications. ${ }^{27}$ The backlog variable has the same effect for eight of ten bidders. The effect differs for two firms: One exception occurs for

25 Under the null the test statistic is a chi-squared random variable with nine degrees of freedom in the probit and it equals 366.75. In the Heckman model the test statistic is a chisquared random variable with 18 degrees of freedom and it equals 388.12. For the Tobit model we constructed an F-test. The test statistic equals 35.35 with $(9,22215)$ degrees of freedom.

26 Under the null, the test statistic is a chi-squared random variable with nine degrees of freedom in the probit and it equals 70.99. In the Heckman model, the test statistic is a chisquared random variable with 18 degrees of freedom and it equals 74.0. For the Tobit model, we constructed an F-test. The test statistic equals 7.42 with $(9,22215)$ degrees of freedom.

27 Under the null, the test statistic is a chi-squared random variable with seven degrees of freedom in the probit and it equals 7.48. The test statistic is a chi-squared random variable with 14 degrees of freedom in the Heckman model and it equals 10.78. For the Tobit model, we construct an F-test. The test statistic equals 0.95 with $(7,22215)$ degrees of freedom. 
firm five, where the sign of the backlog effect is reversed. The other exception occurs for firm eight, where the effect of backlog is of larger magnitude. Overall, we interpret this evidence as partially supportive of our assumption of symmetric behavior conditional on observables.

The estimates in Table 2 provide preliminary support for our dynamic bidding model in at least three ways: First, capacity constraints appear important. Second, bidders' additional state variables, location and size, are important. Third, a test of identical backlog effects cannot be rejected for the majority of bidders.

\section{ESTIMATION RESULTS}

This section discusses the estimates of the econometric model. Subsection 5.1 reports the estimates of the bid distribution functions. We discuss how well the estimates predict the data. We then illustrate the predicted effect of selected variables. Subsection 5.2. discusses the estimates of the value function. Subsection 5.3. discusses the estimates of the bidding function and inferred costs. The estimates suggest that the effect of the backlog variable is in accordance with the expected effect under the presence of capacity constraints. Moreover, the effect is substantial, suggesting that capacity constraints play an important role in highway bidding.

\subsection{ESTIMATES OF THE BID DISTRIBUTION FUNCTIONS}

The parameter estimates are reported in Table 3. Columns one, two and three report the parameter estimates for regular bids, for fringe bids and for the lower bound respectively. Columns four, five and six report the second set of parameter estimates which include additionally a set of firm identity and backlog interaction variables. The variables entering Table 3 are bidders' characteristics and contract characteristics. Bidders' characteristics include the standardized backlog from previously won uncompleted projects, the distance between the closest plant of the bidder to the contract location, and the number of plants within the region of the contract. The contract characteristics include the engineers' estimated cost of the project, the number of working days, the reserve price and the number of fringe bids. Some fringe bids and a small number of regular bids are (substantially) below the engineer's estimate. We believe that these bids represent erroneous bids by inexperienced bidders, or coding errors and we 
omit bid observations that are more than $15 \%$ below the engineer's estimate. ${ }^{28}$ Keeping the bid outliers in the data reduces the lower bound estimate which amplifies the per period payoff estimates, the value function estimates, and also the effect of the backlog variable on the cost estimates. Thus, to the extent that our data selection rule may influence our estimates, our results provide a conservative assessment of the backlog effect.

(Table 3)

As mentioned earlier, we also estimated the bid distribution functions using the consistent but less efficient two stage approach described in Smith (1985). The point estimates are qualitatively similar to the results reported here and are reported in Jofre-Bonet and Pesendorfer (1999).

Goodness of Fit: As a measure of the goodness of fit of the model, we randomly draw bids from the estimated distribution of bids and compare them to the observed bids. To account for contract heterogeneity, we normalize bids by dividing them by the reserve price. The estimates predict well the observed distribution of fringe bids. We draw 10,000 fringe bids. On average, the predicted fringe bid equals $78.01 \%$ of the reserve price with a standard deviation of $11.71 \%$. The observed fringe bid equals $77.72 \%$ of the reserve price with a standard deviation of $11.53 \%$. The difference between the two means is not significant.

The predicted probability of observing a regular bid equals $5.97 \%$. In the data, the probability of observing a regular bid equals 5.96\%. The difference between the two numbers is not significant. Conditional on observing a regular bid, the mean predicted bid equals $82.36 \%$ of the reserve price with a standard deviation of $12.02 \%$. The observed regular bid equals $79.03 \%$ with a standard deviation of $10.40 \%$. We can reject the null hypotheses of equal mean and we reject the null of equal variance. Conditional on observing a regular bid, the predicted bid is, on average, higher and has a higher standard deviation. A closer inspection of the distribution of regular bids conditional on observing a regular bid reveals that the difference between the predicted and observed distribution is attributable to a small fall in the number of

28 In total we omit 25 regular bids and 273 fringe bids. Low bids occur mostly for small contracts and low regular bids do not arise on contracts with engineer's estimates exceeding $\$ 1,000,000$. 
bid observations close to the reserve price. Indeed, a closer fit is obtained when we estimate the bids' distribution function as a product of a Weibull and a Beta distribution functions, instead of the Weibull distribution function that we use. When using the Weibull-Beta alternative specification, we obtain that, conditional on observing a regular bid, the resulting predicted mean bid equals $78.81 \%$ of the reserve price with a standard deviation of $9.81 \%$. For this specification, the observed mean is not significantly different from the predicted mean. The reason for the improvement is that the estimated parameters for the Beta density permit a fall in density close to the reserve price, which improves the fit. But, the Weibull-Beta specification violates the monotonicity assumption of the hazard function which is required by the bidding model. Thus, we decided to impose the monotonicity condition in the estimation and report the estimates obtained using the Weibul distribution function. ${ }^{29}$

The effect of individual variables can be illustrated by evaluating their effect on the probability of submitting a bid at sample average values of explanatory variables. In general, the predicted effect confirms the intuition: The probability of submitting a bid decreases monotonically in backlog, which is consistent with the notion of capacity constraints. An increase in the number of competing fringe firms has a negative effect on the bid submission decision. Distance affects the probability of bid submission negatively, and the number of plants in the region has a positive effect.

29 The fall in the number of bid observations close to the reserve price has at least two explanations: First, bidders do not fully understand the reserve price rule. As described before, about $12 \%$ of all bid observations violate the reserve price requirement, which indicates that at least some bidders did not interpret the reserve price rule correctly. In general, the reserve price rule is complicated, varying with contract size and equaling a fixed dollar amount and a certain percentage (typically 10\%) above the contract's budget. Additionally, a change in the reserve price rule occurred in the middle of the sample period. Second, Caltrans can use a secret reserve price in addition to the announced reserve price rule, by rejecting bids (below the reserve price) that are deemed to high. The data do not substantiate the importance of the secret reserve price rule, as there are no observed bids below the reserve price that were rejected. However, the lack of data may reflect that most winning bids are substantially below the reserve price and does not necessarily indicate the absence of the secret reserve price rule. Both explanations can account for the fall in observations close to the reserve price. Unfortunately, the data are not rich enough to explore these explanations further. For these reasons, we decided to impose the monotonicity requirement in the estimation. 
Backlog: For regular bidders, the backlog variable enters in the scale parameter $\theta_{2}$. Our assumption of symmetric bidding behavior conditional on observables requires that backlog has the same effect across bidders. We can test this assumption using our second set of estimates reported in columns four, five and six in Table 3. This second set of coefficients was estimated including additionally a set of bidder identity and backlog interaction variables. We find that differences in the backlog effect between bidders are not significant for the majority of bidders, reinforcing our earlier evidence in Table 2. An examination of bidder identity and backlog interaction variables reveals that for seven cases out of nine, the bidder specific backlog coefficients are not significantly different from zero. The two significant effects are for firms five and eight. The null of jointly no bidder specific backlog effects is rejected. The test statistic is a chi-squared random variable with nine degrees of freedom and equals 66.72. However, taking only those seven firms with backlog effects not significantly different for zero, the null of jointly no significant backlog effects cannot be rejected. The test statistic is a chi-squared random variable with seven degrees of freedom and equals 7.88 .

(Figure 1)

The effect of the backlog variable on the bid distribution of regular bidders is illustrated in Figure 1. It shows the distribution function between the lower bound of bids and the reserve price and evaluated at sample average values of state variables. Two distribution functions are reported: The solid function assumes a backlog equal to -2 (unconstrained bids) and the dashed function assumes a backlog equal to 2 (constrained bids). The dotted lines represent $90 \%$ confidence intervals. The confidence interval in Figure 1 (and all subsequent estimates' standard errors) are calculated using the delta method. The Figure illustrates that the distribution of constrained bids stochastically dominates, in the first order sense, the distribution of unconstrained bids. On average, unconstrained bidders are about twice as likely to submit a bid than constrained bidders. This finding confirms the importance of capacity constraints. 


\subsection{ESTIMATES OF THE VALUE FUNCTION}

As arguments of the value function approximation we include a three-dimensional vector for each bidder which defines her state. The three dimensional state variables are the bidder's backlog, plant locations and number of plants in all regions.

The value function is defined as the expected sum of future per period payoffs, where expectations are taken over contract characteristics. Per period payoff realizations are a function of bidders' state and the contract characteristics and are evaluated after the contract realization has been observed. The variables entering the per period payoff realization are the variables in Table 3, which include the contract characteristics, bidders' backlogs, bidders' distances to the contract, and bidders' number of plants in the contract's region. Notice that the distance measure entering the value function will differ from the distance measure entering the per period payoff function. The per period payoff function includes the actual distance to the contract, while the value function is evaluated before contract characteristics are known. Thus, plant locations - or the distribution of possible distances induced by the distribution of contract characteristics- are the distance measure entering the value function instead. The same distinction applies to the number of plants per region variable.

We approximate a value function for each bidder $i$ separately. Since, bidder $i$ 's plant locations do not change over time and their level effect is accounted for in the per period payoff function, they do not enter bidder $i$ 's value function approximation as an argument. The same reasoning applies to bidder $i$ 's size measure (number of plants in the region). Thus, the only bidder $i$ 's state variable that remains in bidder $i$ 's value function approximation is bidder $i$ 's backlog.

Thus, taking into account the observations above, the value function is approximated using four components: The bidder's own backlog and three state variables per competitor: Backlog, plant locations, and their number of plants per region. Similarly to bidder $i$ 's own plants and size, competitors' plant locations and number of plants do not have a direct effect on the value function. This effect is already accounted for in the per period payoff function.

As explained in section 3, we make use of the symmetry property to simplify the value function approximation. However, the reduction in dimension by means of the symmetry 
property requires the inclusion of interaction terms between competitor $j$ 's backlog and her plant locations and size (for all $j \neq i$ ). Thus, in bidder $i$ 's value function approximation, there still remains an indirect effect of the competitor's distribution of possible distances to contracts and size in the region. This indirect effect is manifested in the interaction terms involving the competitor's possible distances and size with backlog, which does change from period to period. As measures of each competitor's locations and regional size, we include the average distance to contracts and the average number of plants per region for every competitor. These averages are calculated using the observed contracts. We assume that these variables adequately measure the distribution of distances and the distribution of the number of plants per region.

(Figure 2)

The approximation of the value function for bidder 3 is depicted in Figure 2. We arbitrarily select bidder 3 who is the third largest bidder in dollar value won. We assume the projects are equally spaced over time and since our data contain on average 709 projects per year this assumption implies that a project is offered for sale about every 12 hours. ${ }^{30}$ We impose an annual discount factor of 0.80. In the Figure the competitors' three state variables are fixed at their sample averages. The plot illustrates the discounted expected future profit of bidder 3 by varying the backlog variable of bidder 3 between -1.6 and 1.6. The dotted lines depict the $90 \%$ confidence interval calculated using the delta method. ${ }^{31}$

The average discounted sum of payoffs for bidder 3 equals $\$ 15$ million. Other regular bidders discounted sum of payoffs ranges between $\$ 6$ million and $\$ 59$ million. The assumed annual discount factor of 0.8 is a conservative measure for the effect of the future. Increasing the annual discount factor from 0.8 to 0.9 increases the discounted sum of payoffs by a factor

30 To permit randomness in the timing of projects, a shorter period length could be used and it could be assumed that with a certain probability no projects is offered for sale.

31 To calculate the derivative of the value function with respect to the parameter vector, we take the derivative in equation (3.4) which yields, $V_{i}^{\prime}=A^{\prime}+\beta \sum B_{j}^{\prime} V_{i}+\beta \sum B_{j} V_{i}^{\prime}$. We numerically calculate the derivatives $A^{\prime}$ and $B_{j}^{\prime}$ and the derivative of $V_{i}^{\prime}$ is then given by $V_{i}^{\prime}=\left[A^{\prime}+\beta \sum B_{j}^{\prime} V_{i}\right] /\left[1-\beta \sum B_{j}\right]$ 
of 2, approximately. The accuracy of the computations depend on the fineness of the selected grid of states. Doubling the number of state points, from 200 to 400, alters the value function of bidder 3 by a very small amount only. The difference between the value functions based on 200 and based on 400 states equals at most $1 \%$, or $\$ 180,000$, and the difference equals less than $0.01 \%$ on average which amounts to $\$ 7,600$.

The effect of backlog on the value function in Figure 2 is negative, which is in accordance with the expected effect under capacity constraints. In Figure 2, backlog reduces the value function in total by about $30 \%$. Value function estimates for other bidders are of different magnitude, but in general similar shape. An exception is bidder 5 for which the value function increases initially and then decreases as backlog increases. To illustrate the backlog effect for the average bidder we regress the value functions of bidders evaluated at the 200 states on a set of bidder specific dummy variables and the state variables. To capture possible non-linearities we include both, linear and quadratic coefficients of variables. We find that the predicted value function is about $31 \%$ higher at a backlog level of -1 than at a backlog level of 1 .

\subsection{ESTIMATES OF COSTS}

First, we illustrate the equilibrium bid functions. Then, we describe mark-ups and cost estimates.

(Figure 3)

The equilibrium bid function for bidder 3 is illustrated in Figure 3 . The bid function is estimated using equation (3.2.). The bid function is plotted by fixing the state variables at sample average values for bidder 3 and varying the cost. In addition to the bid function, the 45 degree line is reported. As is evident in the Figure, the bid increases with the cost. In addition, the distance between the bid and the cost decreases as the cost increases. The bid function is of similar shape for other contract characteristics and state variables. In some instances, the difference between bids and costs is large in magnitude at the lower end of the support of bids which can result in a negative cost. We find negative costs implausible and set the cost to zero if the inferred cost would be negative.

The mark-up denotes the difference between the bid and the cost of a bidder. In the 
Figure, the mark-up is the distance between the bid and the 45 degree line. An examination of all observed bids by bidder 3 reveals that the median estimated mark-up for this bidder equals $17.1 \%$ of the bid. The mean mark-up is higher and equals $27.3 \%$ of the bid. The estimated mark-up differs across bidders. The median mark-up across all observed regular bids equals $33.8 \%$ and the mean mark-up equals $40.2 \%$. Although the magnitude of the mark-up may appear large, it appears in accordance with descriptive evidence in Table 1a and Table $1 \mathrm{~b}$. The difference between the lowest and second lowest bid is, on average, $9 \%$ of the value of the bid.

A substantial portion of the mark-up of regular bidders is attributable to the loss in future discounted value due to limited capacity. This loss reflects the cost of winning today versus winning later. We can measure this loss based on equation (3.2.) which decomposes the mark-up into two parts: The first part reflects contemporaneous competition. The second part measures the loss in value of winning today versus winning later. For bidder 3, on average, across all observed bids $43.0 \%$ of the mark-up is attributable to the second part, which is the option value of winning today versus winning later. The number varies across bidders. Across all regular bidders $51.8 \%$ of the mark-up is attributable to the second part.

The mark-up estimates depend on the assumed discount factor. As we increase the annual discount factor, from 0.8 to 0.9 , the following changes take place: For bidder 3 the median estimated mark-up becomes $19.5 \%$ of the bid and the mean mark-up increases to $35.3 \%$ of the bid. The median mark-up across all observed regular bids becomes $36.1 \%$ and the mean mark-up equals $45.6 \%$. Finally, when the discount factor is 0.9 , the option value for bidder $i$ accounts for about $52.1 \%$ of the mark-up, and across all regular bidders for about $55.5 \%$.

(Figure 4)

Costs' Estimates: Figure 4 depicts the distribution function of costs for bidder 3. Distribution functions are reported for two values of backlog and holding other state variables at sample average values. The backlog values are -2 and 2 . The dotted lines represent $90 \%$ confidence intervals which are calculated using the delta method. The estimated cost distribution functions are truncated at the point at which the equilibrium bid corresponding to the cost equals the reserve price and are reported for a common range of costs. Figure 4 documents 
that the cost distribution of the constrained bidder stochastically dominates in the first order sense the cost distribution of the unconstrained bidder. On average, the probability that the cost is below a certain threshold is more than twice when the bidder is unconstrained than when the bidder is constrained. Similar to our earlier evidence in Table 3, we find that cost realization depend not only on the bidder's own state variables, but also on other bidders' state variables. A possible explanation is that shortages of paving workers or shortages of paving equipment caused by high backlog levels of bidders can increase the contract costs for all bidders.

\section{THE EFFECT OF BACKLOG AND INEFFICIENCIES}

This section reports three applications of the estimates: First, we measure the benefits to the auctioneer of increasing capacity of all bidders simultaneously. Second, we measure the short run benefits of individual bidders to an increase in their capacity. Third, we determine to what extent the auction rule does not select the low cost bidder due to the presence of capacity constraints and bidder asymmetries. We quantify the magnitude of resulting inefficiencies.

\subsection{PRICE EFFECT}

We have shown that individual regular bids, costs and future profits depend on the backlog level. Next, we report the hypothetical effect on the price paid for the service by the auctioneer as the backlog level of all regular bidders is increased simultaneously. We may interpret the effect as the benefit to the auctioneer of an increase in capacity of all bidders. We report the price effect for a hypothetical contract on which the fringe bidders are absent. Due to the absence of fringe bidders, the price equals the low regular bid which is the low bid submitted from the set of regular bids. The reason why we select a contract on which the fringe bidders are absent is that their dependence on backlog was not modeled, as fringe bidders' backlog level is not observed in our data.

To compute the price effect we conduct the following exercise: We select the contract with an engineers' cost estimate equal to the sample average. For each regular firm, we randomly draw a bid from the bid distribution under the assumption that their backlog equals -2 . Then, we calculate the price which equals the low bid from this set of regular bids. Similarly, we 
randomly draw bids from the bid distributions of regular bidders under the assumption that their backlog equals 2. Then, we determine this draw's low regular bid. We repeat this sampling procedure to obtain 1,000 observations. Finally, we compare the distribution of prices between both cases.

The price effect is substantial. When backlog of all regular bidders equals -2 , the average price equals $\$ 539,845$. When backlog equals 2 , the average price increases to $\$ 657,016$. The difference in the mean is significant and equals about $18 \%$ of the average at the -2 backlog level.

We repeat the above calculations for backlog levels equal to -1 and 1 . The difference in the average of the price between backlogs of -1 and +1 is significant and equals about $12 \%$ of the average price at a backlog of -1 . We also conducted the experiment for other engineers' cost estimates with similar results.

We can conclude that the benefits to the auctioneer of an increase in available bidder capacity is substantial. Next we examine the effect of available capacity on bidders' returns.

\subsection{PERIOD RETURNS}

We illustrate the effect of available capacity on the ex ante expected period return of an individual regular bidder. The benefits of an additional unit of capacity is an important part in the equation that determines the optimal capacity choice as a function of the returns to capacity and the cost of investing in capacity. The cost of additional capacity in the highway paving industry is difficult to measure and we do not attempt to quantify it. However, our estimates permit us to assess the short run auction returns due to a reduction in backlog and holding total bidder capacity fixed. We calculate the ex ante expected period auction return before contract characteristics and costs are observed. We emphasize that the exercise looks at one auction only. The long run effect of backlog on bidders' returns were illustrated earlier in the discussion of the value function estimates in Section 5.2. and exemplified in Figure 2.

The period returns are defined as the first expression on the right hand side in equation (3.1.). Due to our conditional symmetry assumption, variations in period returns are entirely determined by variations in the state variables. To assess bidder specific returns, we take a 
sample of 200 random draws from the observed distribution of states for each regular bidder and we obtain the short run auction return corresponding to each one of the 200 states, for each regular bidder. Our calculations indicate that regular bidders expect to receive $\$ 9,200$ per contract on average, but there is substantial variation in ex ante expected returns for individual regular bidders ranging between $\$ 2,000$ and $\$ 18,400$ across bidders.

The effect of available capacity on ex ante expected returns can be illustrated by regressing these ex ante period returns on a set of bidder specific dummy variables and the state variables. To capture possible non-linearities we include both linear and quadratic coefficients of the state variables. Using the estimated backlog coefficient, we conduct counterfactual predictions by varying the backlog level, while holding the other variables constant at sample average.

We find that the ex ante expected period payoffs are about $127 \%$ higher if backlog equals -2 than if the backlog equals 2, they are about $71 \%$ higher if backlog equals -1 than if the backlog equals 2 , they are about $32 \%$ higher when backlog equals 0 than if the backlog equals

2 , and they are about $8 \%$ higher when backlog equals 1 than if the backlog equals 2 . If we compare the effects to our earlier results on the value function, we can conclude that the effect of capacity is of larger magnitude in the short run than in the long run.

The illustration shows that available capacity is important in the bidders calculus of bidding.

\subsection{INEFFICIENCIES}

Next, we assess the magnitude of the inefficiencies. Notice, that due to the presence of intertemporal effects and due to bidder heterogeneity, a first-price auction need not select the efficient firm. The bidder with the lowest bid need not be the bidder with the lowest cost. The reason is that constrained (or smaller) bidders may bid more aggressively than unconstrained (or larger) bidders. The strategic bid shading can imply that a constrained firm wins although it did not have the lowest cost.

To assess the magnitude of inefficiencies at auction $t$, we conduct the following experiment: We select the firm that minimizes costs at auction $t$ and take as given that the first- 
price auction is used at auction $t+1$ and onwards. This selection rule gives us a lower bound on the efficiency loss. ${ }^{32}$ To assess which firm to select, we take into account contemporary and future costs. Contemporary costs are those implied by the observed bids. The discounted sum of expected future costs, $V^{c}$, are approximated using the estimates reported in section 5. Specifically, the discounted sum of expected future costs can be written as, $V^{c}(s)=\mathrm{E}_{s_{0}}\left\{\int \phi\left(., s_{0}, s\right) d G_{(1)}\left(. \mid s_{0}, s\right)+\beta \sum_{j=0}^{n_{F}} \operatorname{Pr}\left(j\right.\right.$ wins $\left.\left.\mid s_{0}, s\right) V^{c}\left(\omega\left(s_{0}, s, j\right)\right)\right\}$, where $G_{(1)}\left(. \mid s_{0}, s\right)$ denotes the distribution function of the winning bid on contract $s_{0}$ with state $s$. We evaluate $V^{c}$ numerically in the same way as the value function. The low cost firm is the firm $j$ that minimizes $c_{j}+\beta V^{c}\left(\omega\left(s_{0}, s, j\right)\right)$.

( Table 4)

Table 4 reports the frequency and the inefficiencies' dollar amounts associated with the experiments. We perform the experiment for all observed contract characteristics, except contracts which we omitted in the estimation of the bid distribution functions due to suspiciously low bids, and using the observed bid data. Inefficiencies are reported as a fraction of the initial engineers' estimate. On 35\% of all experiments, an inefficient bidder is selected. We decompose the efficiency loss into contemporary and future cost effects. We find that the inefficiency arises because a lower cost firm could have been chosen in auction $t$. The effect on future costs is negligible. The average efficiency loss across experiments amounts to $18 \%$ of the engineers' estimate. In dollar value, this amounts to $\$ 423,060$ per experiment, on average. In addition to the overall results, Table 4 reports efficiency losses for a range of selected engineers' estimate values. In general, inefficiencies arise for small and large contracts. Nevertheless, inefficiencies, measured in percent of engineers' estimate, are of larger magnitude for larger contracts. Table 4 also reports efficiency losses for two subsets of the data: Contracts won by regular bidders and contracts won by fringe bidders. Table 4 illustrates that the probability of inefficiencies is about the same if a contract is won by a regular bidder than when it is won by a fringe bidder.

32 The full cost minimizing problem is a dynamic decision problem involving ten state variables, one backlog variable for each regular bidder. This problem is too complex for the computing techniques available. 


\section{CONCLUSIONS}

This paper proposes an estimation method for a repeated auction game under the presence of capacity constraints and bidder asymmetry. We apply the method to highway procurement auctions in California. We characterize costs as a function of state variables and illustrate the bidding equilibrium. The data suggests the presence of capacity constraints. Bidders that

have a large fraction of their capacity committed have, on average, higher costs than bidders with little capacity committed. We find that when all bidders are capacity constrained, the resulting price paid by the auctioneer is about $18 \%$ higher than when all regular bidders are unconstrained. Moreover, an individual bidder expects to receive about twice as much from an auction in which the bidder is unconstrained than from an auction in which the bidder is constrained.

There are at least two policy implications from our analysis: First, scheduling and timing of contracts offered for sale influences the final price. Preventing that bidders operate close to the capacity constraint may save costs. Second, due to intertemporal constraints and bidder heterogeneity, an inefficient firm may be chosen. Our experiments indicate that inefficiencies may arise on about $35 \%$ of all contracts and they may amount to $18 \%$ of the expected contract size. Our estimates suggest that auction rules that cope better with intertemporal effects and bidder asymmetry could be a cost saving alternative.

There are two shortcomings of our estimation method: First, possibly the most important assumption in our estimation method is that bidders completely understand the auction environment and that our estimates of winning probabilities correctly capture bidders' perceived winning odds. While we feel that these assumptions are reasonable in our context, we emphasize that our data are too limited to test the adequacy of these assumptions beyond some regularity conditions that our data do satisfy. It may be fruitful to assess the accuracy of the models' predictions with data on independent and reliable information on the perceived winning odds and bidders' cost estimates. Second, our estimation method does not identify the discount factor. The non-identification problem of the discount factor is similar to other dynamic estimation approaches, see Rust (1994). 


\section{APPENDIX}

The appendix contains the proofs to all propositions in the text as well as an auxiliary result.

\section{Subsection 3.1.: Equation (3.2.)}

The probability that bidder $i$ assigns to the event that bidder $j$ wins the contract when bidder $i$ bids $b$, can be written as $\int_{\underline{b}}^{b} g\left(x \mid s_{0}, s_{j}, s_{-j}\right) \prod_{l \neq i, j}\left[1-G\left(x \mid s_{0}, s_{l}, s_{-l}\right)\right] d x$. The first order condition of equilibrium bids by a regular bidder is given by:

$$
\begin{gathered}
{[b-c] \cdot \sum_{j \neq i} \prod_{l \neq i, j}\left[1-G\left(b \mid s_{0}, s_{l}, s_{-l}\right)\right]\left[-g\left(b \mid s_{0}, s_{j}, s_{-j}\right)\right]+\prod_{j \neq i}\left[1-G\left(b \mid s_{0}, s_{j}, s_{-j}\right)\right]+} \\
+\beta V_{i}\left(\omega\left(s_{0}, s, i\right)\right) \sum_{j \neq i} \prod_{l \neq i, j}\left[1-G\left(b \mid s_{0}, s_{l}, s_{-l}\right)\right]\left[-g\left(b \mid s_{0}, s_{j}, s_{-j}\right)\right]+ \\
+\beta \sum_{j \neq i}\left[g\left(b \mid s_{0}, s_{j}, s_{-j}\right) \prod_{l \neq i, j}\left[1-G\left(b \mid s_{0}, s_{l}, s_{-l}\right)\right] \cdot V_{i}\left(\omega\left(s_{0}, s, j\right)\right)\right]=0 .
\end{gathered}
$$

We can rearrange this expression by dividing by $\prod_{l \neq i}\left[1-G\left(b \mid s_{0}, s_{l}, s_{-l}\right)\right]$. This yields:

$$
\begin{gathered}
{[b-c] \cdot \sum_{j \neq i} \frac{-g\left(b \mid s_{0}, s_{j}, s_{-j}\right)}{1-G\left(b \mid s_{0}, s_{j}, s_{-j}\right)}+1+\beta V_{i}\left(\omega\left(s_{0}, s, i\right)\right) \sum_{j \neq i} \frac{-g\left(b \mid s_{0}, s_{j}, s_{-j}\right)}{1-G\left(b \mid s_{0}, s_{j}, s_{-j}\right)}+} \\
+\beta \sum_{j \neq i} \frac{g\left(b \mid s_{0}, s_{j}, s_{-j}\right)}{1-G\left(b \mid s_{0}, s_{j}, s_{-j}\right)} \cdot V_{i}\left(\omega\left(s_{0}, s, j\right)\right)=0 .
\end{gathered}
$$

The hazard function, $h\left(. \mid s_{0}, s_{j}, s_{-j}\right)=\frac{g\left(. \mid s_{0}, s_{j}, s_{-j}\right)}{1-G\left(. \mid s_{0}, s_{j}, s_{-j}\right)}$ can be substituted into this equation. This substitution yields equation (3.2.).

The first order condition for optimal bids by a fringe bidder is obtained in analogous way. In particular, evaluating (A3.2) at $V_{i}=0$, gives the corresponding first order condition of a fringe bidder. 


\section{Proof of Proposition 1:}

To establish the claim in the proposition, we show that the value function, defined in equation (3.1.), has a representation in terms of the distribution of bids. There are two steps involved: First, we make use of the first order condition of optimal bids. This condition provides us with an explicit expression of the cost in terms of bids and the value function. Second, we change the range of integration from the cost space to the bid space. The resulting equation (3.3.) characterizes the value function as an infinite sum.

Note that the probability that bidder $i$ assigns to the event that bidder $j$ wins the contract when bidder $i$ bids $b, \operatorname{Pr}\left(j\right.$ wins $\left.\mid b, s_{0}, s_{i}, s_{-i}\right)$, can be written as: $\int_{\underline{b}}^{b} g\left(x \mid s_{0}, s_{j}, s_{-j}\right) \prod_{l \neq i, j}[1-$ $\left.G\left(x \mid s_{0}, s_{l}, s_{-l}\right)\right] d x$. In an abuse of notation, we denote by $b(c)$ the equilibrium bid by bidder $i$ on contract $s_{0}$ if the state is $s$. We can substitute the first order condition for optimal bids, equation (3.2.), into the value function, equation (3.1.). Notice that we can use the first order condition only for costs such that the equilibrium bid is below the reserve price. If the equilibrium bid equals or exceeds the reserve price, then the bid is rejected and the current period payoff equals zero. We account for this distinction explicitly by including an indicator function $\mathbf{1}_{A}$ that equals one if event $A$ is true and equals zero, otherwise. Doing so yields:

$$
\begin{aligned}
V_{i}(s)=E_{0}\left\{\int\right. & {\left[\frac{1-\beta \sum_{j \neq i} h\left(b(c) \mid s_{0}, s_{j}, s_{-j}\right)\left[V_{i}\left(\omega\left(s_{0}, s, i\right)\right)-V_{i}\left(\omega\left(s_{0}, s, j\right)\right)\right]}{\sum_{j \neq i} h\left(b(c) \mid s_{0}, s_{j}, s_{-j}\right)} .\right.} \\
& \cdot \operatorname{Pr}\left(i \text { wins } \mid b(c), s_{0}, s_{i}, s_{-i}\right) \mathbf{1}_{\left\{b(c) \leq R\left(s_{0}\right)\right\}}+0 \cdot \mathbf{1}_{\left\{b(c)>R\left(s_{0}\right)\right\}} \\
& \left.\left.+\beta \sum_{j=0}^{n_{F}} \operatorname{Pr}\left(j \operatorname{wins} \mid b(c), s_{0}, s_{i}, s_{-i}\right) V_{i}\left(\omega\left(s_{0}, s, j\right)\right)\right] \cdot f\left(c \mid s_{0}, s_{i}, s_{-i}\right) d c\right\} .
\end{aligned}
$$

Note that the expression $\int \beta\left[\sum_{j=0}^{n_{F}} \operatorname{Pr}\left(j\right.\right.$ wins $\left.\mid b(c), s_{i}, s_{-i}\right) V_{i}\left(\omega\left(s_{0}, s, j\right)\right) f\left(c \mid s_{0}, s_{i}, s_{-i}\right) d c$ is the ex ante expected value of $\beta \sum_{j=0}^{n_{F}} \operatorname{Pr}\left(j\right.$ wins $\left.\mid s_{0}, s_{i}, s_{-i}\right) V_{i}\left(\omega\left(s_{0}, s, j\right)\right)$, and that the term involving bids above the reserve price, $0 \cdot \mathbf{1}_{\left\{b(c)>R\left(s_{0}\right)\right\}}$, vanishes. Furthermore, the expression $\frac{\sum_{j \neq i} h\left(b(c) \mid s_{0}, s_{j}, s_{-j}\right) V_{i}\left(\omega\left(s_{0}, s, i\right)\right)}{\sum_{j \neq i} h\left(b(c) \mid s_{0}, s_{j}, s_{-j}\right)}$ reduces to $V_{i}\left(\omega\left(s_{0}, s, i\right)\right)$ and cancels with the second term in- 
volving $V_{i}\left(\omega\left(s_{0}, s, i\right)\right)$. By making these changes, we can write the value function as:

$$
\begin{aligned}
V_{i}(s)=E_{0}\left\{\int\right. & {\left[\frac{1+\beta \sum_{j \neq i} h\left(b(c) \mid s_{0}, s_{j}, s_{-j}\right) V_{i}\left(\omega\left(s_{0}, s, j\right)\right)}{\sum_{j \neq i} h\left(b(c) \mid s_{0}, s_{j}, s_{-j}\right)}\right] \cdot \operatorname{Pr}\left(i \text { wins } \mid b(c), s_{0}, s_{i}, s_{-i}\right) . } \\
\cdot & \left.\mathbf{1}_{\left\{b(c) \leq R\left(s_{0}\right)\right\}} f\left(c \mid s_{0}, s_{i}, s_{-i}\right) d c+\beta \sum_{j \neq i} \operatorname{Pr}\left(j \text { wins } \mid s_{0}, s_{i}, s_{-i}\right) V_{i}\left(\omega\left(s_{0}, s, j\right)\right)\right\} .
\end{aligned}
$$

Next consider a change of variable of integration from $c$ to $b$. Notice that $d b=\frac{\partial b(c)}{\partial c} d c$. Let $b^{-1}$ denote the inverse function of the equilibrium bid function. By assumption the inverse bidding function exists for bids below the reserve price. The inverse bidding function allows us to write the distribution function of cost in terms of the distribution functions of bids. Specifically, $F\left(b^{-1}(b) \mid s_{0}, s_{i}, s_{-i}\right)=G\left(b \mid s_{0}, s_{i}, s_{-i}\right)$. Taking the partial derivative yields a relationship between the density of costs and bids: $f\left(b^{-1}(b) \mid s_{0}, s_{i}, s_{-i}\right) \cdot \frac{\partial b^{-1}(b)}{\partial b}=g\left(b \mid s_{0}, s_{i}, s_{-i}\right)$. Also, notice that $\frac{\partial b^{-1}(b)}{\partial b}=\frac{1}{\frac{\partial b(c)}{\partial c}}$. Finally, the probability that bidder $i$ wins can be written as $\operatorname{Pr}\left(i\right.$ wins $\left.\mid b, s_{0}, s_{i}, s_{-i}\right)=\prod_{j \neq i}\left[1-G\left(b \mid s_{0}, s_{j}, s_{-j}\right)\right]$. Applying the change of variables in the above equation yields:

$$
\begin{aligned}
V_{i}(s) & =E_{0}\left\{\int_{\underline{b}}^{R} \frac{\prod_{k \neq i}\left[1-G\left(b \mid s_{0}, s_{k}, s_{-k}\right)\right]}{\sum_{j \neq i} h\left(b \mid s_{0}, s_{j}, s_{-j}\right)} g\left(b \mid s_{0}, s_{i}, s_{-i}\right) d b\right. \\
& +\beta \int_{\underline{b}}^{R}\left[\sum_{j \neq i} \frac{h\left(b \mid s_{0}, s_{j}, s_{-j}\right) \cdot V_{i}\left(\omega\left(s_{0}, s, j\right)\right)}{\sum_{l \neq i} h\left(b \mid s_{0}, s_{l}, s_{-l}\right)}\right] \prod_{k \neq i}\left[1-G\left(b \mid s_{0}, s_{k}, s_{-k}\right)\right] \cdot g\left(b \mid s_{0}, s_{i}, s_{-i}\right) d b \\
& \left.+\beta \sum_{j \neq i} \operatorname{Pr}\left(j \text { wins } \mid s_{0}, s_{i}, s_{-i}\right) V_{i}\left(\omega\left(s_{0}, s, j\right)\right)\right\} .
\end{aligned}
$$

Observe that the expression in the second line of the value function can be rewritten, by taking the sum $\sum_{j \neq i}$ outside, multiplying the expression by $\frac{1-G\left(b \mid s_{0}, s_{i}, s_{-i}\right)}{1-G\left(b \mid s_{0}, s_{i}, s_{-i}\right)}$ and $\frac{g\left(b \mid s_{0}, s_{j}, s_{-j}\right)}{g\left(b \mid s_{0}, s_{j}, s_{-j}\right)}$, and rearranging terms, as:

$$
\beta \sum_{j \neq i}\left[\int_{\underline{b}(s)}^{R} \frac{h\left(b \mid s_{0}, s_{i}, s_{-i}\right)}{\sum_{l \neq i} h\left(b \mid s_{0}, s_{l}, s_{-l}\right)} \prod_{l \neq j}\left[1-G\left(b \mid s_{0}, s_{l}, s_{-l}\right)\right] \cdot g\left(b \mid s_{0}, s_{j}, s_{-j}\right) d b\right] \cdot V_{i}\left(\omega\left(s_{0}, s, j\right)\right) .
$$


Finally, observe that $\prod_{l \neq j}\left[1-G\left(b \mid s_{0}, s_{l}, s_{-l}\right)\right] g\left(b \mid s_{0}, s_{j}, s_{-j}\right)$ is the probability density function that a bid of bidder $j$ is the low bid, $d G^{(j)}\left(b \mid s_{0}, s\right)$, which yields the expression (3.3.) in the Proposition.

QED

Proof of Proposition 2: Suppose there are two cost distribution functions $F_{1}(. \mid$.$) and$ $F_{2}(. \mid$.$) with support \left[\underline{C}_{1}\left(s_{0}^{t}, s_{i}^{t}, s_{-i}^{t}\right), \bar{C}_{1}\left(s_{0}^{t}, s_{i}^{t}, s_{-i}^{t}\right)\right]$ and $\left[\underline{C}_{2}\left(s_{0}^{t}, s_{i}^{t}, s_{-i}^{t}\right), \bar{C}_{2}\left(s_{0}^{t}, s_{i}^{t}, s_{-i}^{t}\right)\right]$ respectively, such that both distribution lead to the same bid distribution function $G(. \mid$.) on the interval $\left[\underline{b}\left(s_{0}^{t}, s^{t}\right), R^{t}\right]$. By assumption, an equilibrium in monotone strategies exists and the discount factor is known. The necessary first order condition of equilibrium bids (3.2.) implies that:

$$
\begin{aligned}
& \underline{C}_{1}\left(s_{0}^{t}, s_{i}^{t}, s_{-i}^{t}\right)=\phi\left(\underline{b}\left(s_{0}^{t}, s^{t}\right) \mid s_{0}^{t}, s_{i}^{t}, s_{-i}^{t}, \beta, G\right) \\
& \underline{C}_{2}\left(s_{0}^{t}, s_{i}^{t}, s_{-i}^{t}\right)=\phi\left(\underline{b}\left(s_{0}^{t}, s^{t}\right) \mid s_{0}^{t}, s_{i}^{t}, s_{-i}^{t}, \beta, G\right)
\end{aligned}
$$

and it follows that $\underline{C}_{1}\left(s_{0}^{t}, s_{i}^{t}, s_{-i}^{t}\right)=\underline{C}_{2}\left(s_{0}^{t}, s_{i}^{t}, s_{-i}^{t}\right)$.

Furthermore, for any $\left(s_{0}^{t}, s_{i}^{t}, s_{-i}^{t}\right)$ and any $b \leq R^{t}$, equation (3.2.) yields $c=$ $\phi\left(b \mid s_{0}^{t}, s_{i}^{t}, s_{-i}^{t}, \beta, G\right)$, and therefore,

$$
\begin{aligned}
& F_{1}\left(c \mid s_{0}^{t}, s_{i}^{t}, s_{-i}^{t}\right)=G\left(\phi^{-1}\left(c \mid s_{0}^{t}, s_{i}^{t}, s_{-i}^{t}, \beta, G\right) \mid s_{0}^{t}, s_{i}^{t}, s_{-i}^{t}\right) \\
& F_{2}\left(c \mid s_{0}^{t}, s_{i}^{t}, s_{-i}^{t}\right)=G\left(\phi^{-1}\left(c \mid s_{0}^{t}, s_{i}^{t}, s_{-i}^{t}, \beta, G\right) \mid s_{0}^{t}, s_{i}^{t}, s_{-i}^{t}\right) .
\end{aligned}
$$

It follows that $F_{1}=F_{2}$ on the interval $\left[\underline{C}(),. \phi\left(R^{t} \mid.\right)\right]$.

Q.E.D. 


\section{REFERENCES}

Athey, S. (2001): "Single Crossing Properties and the Existence of Pure Strategy Equilibria in Games of Incomplete Information," Econometrica, Vol. 69, No. 4, 861-889.

Bajari, P. (1997): "Econometrics of the First Price Auction with Asymmetric Bidders," mimeo, Stanford University.

Bhattacharya, R. N. and Majumdar, M. (1989): "Controlled Semi-Markov Models - The Discounted Case," Journal of Statistical Planning and Inference, 21, 365-381.

Billingsley, P. (1961): "Statistical Inference for Markov Processes," Chicago: University of Chicago Press.

Berry, S. and Pakes, A. (2000): "Using First Order Conditions to Estimate Dynamic Oligopoly Models," mimeo, Yale University, May 2000.

Donald, S. G. and Paarsch H.J. (1993): "Piecewise Pseudo-Maximum Likelihood Estimation in Empirical Models of Auctions," International Economics Review, Vol. 34, No. 1, 121-148.

Donald, S. G., Paarsch H.J. and Robert, J. (1997): "Identification, Estimation, and Testing in Empirical Models of Sequential, Ascending-Price Auctions with Multi-Unit Demand: An Application to Siberian Timber-Export Permits," mimeo, University of Iowa.

Elyakime, B., Laffont J.J., Loisel P. and Vuong, Q. (1994): "First-Price Sealed-Bid Auctions with Secret Reservation Prices," Annales d'Economie et de Statistique, 34, 115-141.

Feinstein, J.S., Block, Michael K. and Nold, Frederick C. (1985): “Asymmetric Information and Collusive Behavior in Auction Markets," American Economic Review, Vol. 75, No. $3,441-460$.

Guerre E., Perrigne I. and Vuong, Q. (2000): "Optimal Nonparametric Estimation of FirstPrice Auctions," Econometrica, Vol. 68, No. 3, 525-574.

Harter, H.L. and Moore, A.H. (1965): "Maximum Likelihood estimation of the parameters of the Gamma and Weibull Populations from Complete and from Censored Samples", Technometrics, 7, 639-643.

Hendricks, K. and Porter, R. H. (1988): "An Empirical Study of an Auction with Asymmetric Information," American Economic Review, Vol. 78, 865-883.

Hendricks, K., Pinske, J. and Porter, R. H. (2000): "Empirical Implications of Equilibrium 
Bidding in First-Price, Symmetric, Common Value Auctions," Working Paper No. 0008, The Center for the Study of Industrial Organization, Northwestern University.

Hotz, C. and Miller R. (1993): "Conditional Choice Probabilities and the Estimation of Dynamic Models" Review of Economic Studies, Vol. 60, No. 3, 497-529..

Jofre-Bonet, M. and Pesendorfer, M. (2000): "Bidding Behavior in a Repeated Procurement Auction: A Summary," European Economic Review, 44, 1006-1020.

Jofre-Bonet, M. and Pesendorfer, M. (1999): "Bidding Behavior in a Repeated Procurement Auction," mimeo, Yale University.

Judd, K. (1998): Numerical Methods in Economics. MIT Press.

Laffont, J.J., Ossard, H. and Vuong, Q. (1995): "Econometrics of First-Price Auctions," Econometrica, 63(4), 953-980.

Laffont, J.J. and Robert, J. (1999): "Intra-Day Dynamics in Sequential Auctions: Theory," mimeo, Toulouse.

Lebrun, B. (1996): "Existence of Equilibrium in First-Price Auctions," Economic Theory, 7, 421-443.

Maskin, E. and Riley, J. (2000): "Equilibrium in Sealed High Bid Auctions." Review of Economic Studies, 67, 439-454.

Paarsch, H. (1992): "Deciding between the Common and Private Value Paradigms in Empirical Models of Auctions," Journal of Econometrics, 51, 191-215.

Pakes, A. (1994): "Dynamic Structural Models, Problems and Prospects: Mixed Continuous Discrete Controls and Market Interactions," in C. Sims and J. Laffont, Advances in Econometrics, Proceedings of the 1990 Meetings of the Econometric Society, 1994.

Porter, R.H. (1995): "The Role of Information in U.S. Offshore Oil and Gas Lease Auctions," Econometrica, Vol. 63, No. 1, 1-27.

Porter, R.H. and Zona, J. D. (1993): "Detection of Bid Rigging in Procurement Auctions," Journal of Political Economy, 101, pp. 518-538.

Rust, J. (1994): "Structural Estimation of Markov Decision Processes," in Handbook of Econometrics. Vol. 4, Engle, R.F. and McFadden D.L. eds., Elsevier, North-Holland, pages 3081-3143. 
Smith, R. (1985): "Maximum Likelihood Estimation in a Class of Nonregular Cases," Biometrika, 72(1), 67-90.

Smith, R. (1994): "Nonregular Regression," Biometrika, 81(1), 173-183. 
Table 1A: Descriptive Statistics of Selected Variables

\begin{tabular}{lcrrrr}
\hline & $\begin{array}{c}\text { Number of } \\
\text { Observations }\end{array}$ & Mean & $\begin{array}{c}\text { Standard } \\
\text { Deviation }\end{array}$ & Minimum & Maximum \\
\hline Number of Bidders & 2223 & 4.63 & 2.46 & 0.00 & 19.00 \\
Estimate* $^{*}$ (Ranked1*-Estimate)/Estimate & 2223 & 13.41 & 1.35 & 9.47 & 18.31 \\
(Ranked2 $^{\star *}$-Ranked1)/Ranked1 & 2207 & -0.04 & 0.22 & -0.79 & 3.07 \\
Backlog $^{* *}$ & 2111 & 0.09 & 0.12 & 0.00 & 2.62 \\
& 22230 & 0.00 & 1.00 & -3.24 & 2.97 \\
\hline
\end{tabular}

*Logarithm of the engineers' estimate.

**Ranked1 and Ranked2 are the winning bid and the bid ranked in second position, respectively.

***Backlog measures the $\$$ value of previously won uncompleted contracts. It is standardized by subtracting

the bidder specific mean and dividing by the bidder specific standard deviation. 
Table 1B: Descriptive Statistics of Selected Variables by Number of Bidders

\begin{tabular}{|c|c|c|c|c|c|c|c|c|c|c|c|}
\hline & $\begin{array}{l}\text { Number of bidders: } \\
\text { \# Observations: }\end{array}$ & $\frac{\text { All }}{2223}$ & $\begin{array}{l}\mathbf{0} \\
16\end{array}$ & $\frac{1}{96}$ & $\frac{2}{285}$ & $\begin{array}{c}3 \\
393\end{array}$ & $\begin{array}{c}4 \\
432\end{array}$ & $\begin{array}{c}5 \\
356\end{array}$ & $\begin{array}{c}6 \\
237\end{array}$ & $\begin{array}{l}7-8 \\
251\end{array}$ & $\begin{array}{c}9-19 \\
157\end{array}$ \\
\hline \multicolumn{12}{|l|}{ Estimate $^{\star}$} \\
\hline & Mean & 13.41 & & 13.14 & 13.47 & 13.49 & 13.32 & 13.42 & 13.55 & 13.48 & 13.12 \\
\hline \multicolumn{12}{|c|}{ (Ranked1**-Estimate)/Estimate } \\
\hline & Mean & -0.04 & & 0.11 & 0.03 & -0.01 & -0.04 & -0.06 & -0.09 & -0.10 & -0.14 \\
\hline (Ranked2* & $\begin{array}{l}\text { Standard Deviation } \\
\text { nked1)/Ranked1 }\end{array}$ & 0.22 & & 0.36 & 0.29 & 0.21 & 0.20 & 0.19 & 0.16 & 0.20 & 0.16 \\
\hline & Mean & 0.09 & & & 0.14 & 0.11 & 0.09 & 0.08 & 0.06 & 0.07 & 0.06 \\
\hline & Standard Deviation & 0.12 & & & 0.11 & 0.19 & 0.10 & 0.09 & 0.06 & 0.07 & 0.07 \\
\hline
\end{tabular}

*Logarithm of the engineers' estimate.

**Ranked1 and Ranked2 are the winning bid and the bid ranked in second position, respectively. 
Table 2: Bid Subsmission and Bid Level Decisions

\begin{tabular}{|c|c|c|c|c|c|c|c|c|c|}
\hline \multirow{6}{*}{$\begin{array}{l}\text { Estimation Method: } \\
\text { Dependent Variable: } \\
\text { Number of observations: } \\
\text { Chi^2: } \\
\text { Degrees of freedom: } \\
\text { Log Likelihood: } \\
\text { Variable }\end{array}$} & \multicolumn{2}{|c|}{$\begin{array}{c}\text { Probit } \\
\text { Bid Submission }\end{array}$} & \multirow[b]{2}{*}{22230} & \multicolumn{2}{|c|}{$\begin{array}{c}\text { Tobit } \\
\text { (R-Bid)/Estimate* }\end{array}$} & \multicolumn{4}{|c|}{$\begin{array}{c}\text { Heckman } \\
\text { (R-Bid)/Estimate* }\end{array}$} \\
\hline & 22230 & 22230 & & 22230 & 22230 & 22230 & 22230 & 22230 & 22230 \\
\hline & 1605.65 & 1984.17 & 1677.77 & 1518.99 & 1883.42 & 1589.23 & 420.41 & 444.64 & 420.44 \\
\hline & & & & 6 & & 15 & 6 & 15 & \\
\hline & -4281.26 & -4092.39 & -4245.60 & -3765.05 & -3582.84 & -3729.93 & -3404.46 & -3394.35 & -3366.71 \\
\hline & & 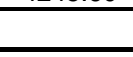 & 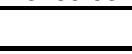 & \multirow{2}{*}{$\begin{array}{r}-1.2511 \\
(0.091)\end{array}$} & \multirow{2}{*}{$\begin{array}{r} \\
-1.1644 \\
(0.089)\end{array}$} & \multirow{2}{*}{$\begin{array}{l} \\
0.3093 \\
(0.072)\end{array}$} & \multirow{2}{*}{$\begin{array}{l} \\
0.2734 \\
(0.076)\end{array}$} & \multirow{2}{*}{$\begin{array}{l} \\
\\
\end{array}$} \\
\hline Constant & $\begin{array}{r}-2.8485 \\
(0.173)\end{array}$ & $\begin{array}{r}-3.169 \\
(0.184)\end{array}$ & $\begin{array}{r}-2.864 \\
(0.174)\end{array}$ & $\begin{array}{r}-1.1654 \\
(0.089)\end{array}$ & & & & & \\
\hline Estimate & $\begin{array}{l}0.2905 \\
(0.015)\end{array}$ & $\begin{array}{l}0.3024 \\
(0.016)\end{array}$ & $\begin{array}{l}0.2902 \\
(0.015)\end{array}$ & $\begin{array}{l}0.1235 \\
(0.008)\end{array}$ & $\begin{array}{l}0.1220 \\
(0.008)\end{array}$ & $\begin{array}{l}0.1250 \\
(0.008)\end{array}$ & $\begin{array}{l}0.0040 \\
(0.006)\end{array}$ & $\begin{array}{l}0.0038 \\
(0.007)\end{array}$ & $\begin{array}{l}0.0032 \\
(0.007)\end{array}$ \\
\hline Working Days & $\begin{array}{r}-0.3176 \\
(0.022)\end{array}$ & $\begin{array}{r}-0.3234 \\
(0.023)\end{array}$ & $\begin{array}{r}-0.3270 \\
(0.023)\end{array}$ & $\begin{array}{r}-0.1498 \\
(0.011)\end{array}$ & $\begin{array}{r}-0.1446 \\
(0.011)\end{array}$ & $\begin{array}{r}-0.1537 \\
(0.011)\end{array}$ & $\begin{array}{r}-0.0533 \\
(0.008)\end{array}$ & $\begin{array}{r}-0.0540 \\
(0.009)\end{array}$ & $\begin{array}{r}-0.0527 \\
(0.008)\end{array}$ \\
\hline Nbid-Fringe & $\begin{array}{r}-0.1835 \\
(0.027)\end{array}$ & $\begin{array}{r}-0.1913 \\
(0.027)\end{array}$ & $\begin{array}{r}-0.1885 \\
(0.027)\end{array}$ & $\begin{array}{r}-0.0882 \\
(0.013)\end{array}$ & $\begin{array}{r}-0.0875 \\
(0.013)\end{array}$ & $\begin{array}{r}-0.0905 \\
(0.013)\end{array}$ & $\begin{array}{r}-0.0613 \\
(0.007)\end{array}$ & $\begin{array}{r}-0.0599 \\
(0.008)\end{array}$ & $\begin{array}{r}-0.0624 \\
(0.008)\end{array}$ \\
\hline Distance & $\begin{array}{r}-0.5193 \\
(0.023)\end{array}$ & $\begin{array}{r}-0.4805 \\
(0.024)\end{array}$ & $\begin{array}{r}-0.5238 \\
(0.023)\end{array}$ & $\begin{array}{r}-0.2536 \\
(0.012)\end{array}$ & $\begin{array}{r}-0.2240 \\
(0.012)\end{array}$ & $\begin{array}{r}-0.2543 \\
(0.012)\end{array}$ & $\begin{array}{r}-0.1196 \\
(0.008)\end{array}$ & $\begin{array}{r}-0.0978 \\
(0.009)\end{array}$ & $\begin{array}{r}-0.1188 \\
(0.009)\end{array}$ \\
\hline \# Plants within Region & $\begin{array}{l}0.1807 \\
(0.051)\end{array}$ & $\begin{array}{l}0.0513 \\
(0.054)\end{array}$ & $\begin{array}{l}0.1786 \\
(0.052)\end{array}$ & $\begin{array}{l}0.0638 \\
(0.025)\end{array}$ & $\begin{array}{l}0.0078 \\
(0.024)\end{array}$ & $\begin{array}{l}0.0632 \\
(0.024)\end{array}$ & $\begin{array}{r}-0.0051 \\
(0.014)\end{array}$ & $\begin{array}{r}-0.0193 \\
(0.015)\end{array}$ & $\begin{array}{r}-0.0052 \\
(0.015)\end{array}$ \\
\hline Backlog & $\begin{array}{r}-0.0835 \\
(0.015)\end{array}$ & $\begin{array}{r}-0.0856 \\
(0.015)\end{array}$ & $\begin{array}{r}-0.1079 \\
(0.053)\end{array}$ & $\begin{array}{r}-0.0383 \\
(0.007)\end{array}$ & $\begin{array}{r}-0.0372 \\
(0.007)\end{array}$ & $\begin{array}{r}-0.0528 \\
(0.025)\end{array}$ & $\begin{array}{r}-0.0127 \\
(0.004)\end{array}$ & $\begin{array}{r}-0.0127 \\
(0.005)\end{array}$ & $\begin{array}{r}-0.0162 \\
(0.017)\end{array}$ \\
\hline Firm_2 & & $\begin{array}{l}0.6784 \\
(0.061)\end{array}$ & & & $\begin{array}{l}0.2985 \\
(0.029)\end{array}$ & & & $\begin{array}{l}0.1204 \\
(0.019)\end{array}$ & \\
\hline Firm_3 & & $\begin{array}{r}-0.0338 \\
(0.073)\end{array}$ & & & $\begin{array}{r}-0.0081 \\
(0.034)\end{array}$ & & & $\begin{array}{r}-0.0223 \\
(0.024)\end{array}$ & \\
\hline Firm_4 & & $\begin{array}{l}0.1499 \\
(0.074)\end{array}$ & & & $\begin{array}{l}0.0649 \\
(0.034)\end{array}$ & & & $\begin{array}{l}0.0011 \\
(0.022)\end{array}$ & \\
\hline Firm_5 & & $\begin{array}{r}-0.0325 \\
(0.073)\end{array}$ & & & $\begin{array}{r}-0.0133 \\
(0.033)\end{array}$ & & & $\begin{array}{r}-0.0097 \\
(0.023)\end{array}$ & \\
\hline Firm_6 & & $\begin{array}{r}-0.1885 \\
(0.076)\end{array}$ & & & $\begin{array}{r}-0.0976 \\
(0.035)\end{array}$ & & & $\begin{array}{r}-0.0458 \\
(0.023)\end{array}$ & \\
\hline Firm_7 & & $\begin{array}{l}0.2011 \\
(0.072)\end{array}$ & & & $\begin{array}{l}0.0969 \\
(0.033)\end{array}$ & & & $\begin{array}{l}0.0054 \\
(0.022)\end{array}$ & \\
\hline Firm_8 & & $\begin{array}{r}-0.0515 \\
(0.073)\end{array}$ & & & $\begin{array}{r}-0.0212 \\
(0.034)\end{array}$ & & & $\begin{array}{r}-0.0357 \\
(0.023)\end{array}$ & \\
\hline Firm_9 & & $\begin{array}{r}-0.2070 \\
(0.077)\end{array}$ & & & $\begin{array}{r}-0.0893 \\
(0.035)\end{array}$ & & & $\begin{array}{r}-0.0372 \\
(0.023)\end{array}$ & \\
\hline Firm_10 & & $\begin{array}{l}0.2277 \\
(0.069)\end{array}$ & & & $\begin{array}{l}0.1297 \\
(0.031)\end{array}$ & & & $\begin{array}{l}0.0742 \\
(0.021)\end{array}$ & \\
\hline Backlog_2 & & & $\begin{array}{l}0.0345 \\
(0.072)\end{array}$ & & & $\begin{array}{l}0.0214 \\
(0.034)\end{array}$ & & & $\begin{array}{l}0.0065 \\
(0.022)\end{array}$ \\
\hline Backlog_3 & & & $\begin{array}{r}-0.0239 \\
(0.063)\end{array}$ & & & $\begin{array}{l}0.0033 \\
(0.030)\end{array}$ & & & $\begin{array}{l}0.0015 \\
(0.019)\end{array}$ \\
\hline Backlog_4 & & & $\begin{array}{r}-0.0637 \\
(0.078)\end{array}$ & & & $\begin{array}{r}-0.0338 \\
(0.037)\end{array}$ & & & $\begin{array}{r}-0.0258 \\
(0.024)\end{array}$ \\
\hline Backlog_5 & & & $\begin{array}{l}0.3193 \\
(0.070)\end{array}$ & & & $\begin{array}{l}0.1530 \\
(0.034)\end{array}$ & & & $\begin{array}{l}0.0591 \\
(0.023)\end{array}$ \\
\hline Backlog_6 & & & $\begin{array}{l}0.0495 \\
(0.076)\end{array}$ & & & $\begin{array}{l}0.0256 \\
(0.034)\end{array}$ & & & $\begin{array}{r}-0.0072 \\
(0.024)\end{array}$ \\
\hline Backlog_7 & & & $\begin{array}{l}0.0970 \\
(0.074)\end{array}$ & & & $\begin{array}{l}0.0458 \\
(0.035)\end{array}$ & & & $\begin{array}{l}0.0128 \\
(0.023)\end{array}$ \\
\hline Backlog_8 & & & $\begin{array}{r}-0.2357 \\
(0.075)\end{array}$ & & & $\begin{array}{r}-0.1117 \\
(0.036)\end{array}$ & & & $\begin{array}{r}-0.0344 \\
(0.024)\end{array}$ \\
\hline Backlog_9 & & & $\begin{array}{l}0.0546 \\
(0.071)\end{array}$ & & & $\begin{array}{l}0.0261 \\
(0.034)\end{array}$ & & & $\begin{array}{l}0.0018 \\
(0.024)\end{array}$ \\
\hline Backlog_10 & & & $\begin{array}{r}-0.0195 \\
(0.071)\end{array}$ & & & $\begin{array}{r}-0.0075 \\
(0.030)\end{array}$ & & & $\begin{array}{r}-0.0096 \\
(0.022)\end{array}$ \\
\hline Mills Ratio & & & & & & & $\begin{array}{l}0.2342 \\
(0.011)\end{array}$ & $\begin{array}{l}0.2233 \\
(0.011)\end{array}$ & $\begin{array}{l}0.2319 \\
(0.011)\end{array}$ \\
\hline
\end{tabular}

All variables except Backlog are in logarithm. The numbers in parenthesis are standard deviations.

*(R-Bid)/Estimate denotes the logarithm of the variable (Reserve price minus the Bid) over the engineers' Estimate plus one. 
Table 3: Parameter Estimates of the Bid Distributions

\begin{tabular}{|c|c|c|c|c|c|c|}
\hline $\begin{array}{l}\text { Data: } \\
\text { Number of Observations: } \\
\text { Log Likelihood: }\end{array}$ & $\begin{array}{r}\text { Regular and } \\
30,8 \\
-1,46\end{array}$ & $\begin{array}{l}\text { Fringe Bids } \\
873 \\
7.46\end{array}$ & & $\begin{array}{r}\text { Regular and } \mathrm{F} \\
30,8 \\
-1,500\end{array}$ & $\begin{array}{l}\text { Fringe Bids } \\
73 \\
0.82\end{array}$ & \\
\hline Variables & Regular Bids & Fringe Bids & Lower Bound & Regular Bids & Fringe Bids & Lower Bound \\
\hline$\theta_{1}$ & $\begin{array}{r}-13.1688 \\
(22.689)\end{array}$ & & & $\begin{array}{r}-13.1721 \\
(14.779)\end{array}$ & & \\
\hline$\theta_{4}$ & & $\begin{array}{r}-1.3354 \\
(0.155)\end{array}$ & & & $\begin{array}{r}-1.3357 \\
(0.154)\end{array}$ & \\
\hline Constant & $\begin{array}{l}5.6934 \\
(0.193)\end{array}$ & $\begin{array}{c}1.8821 \\
(0.170)\end{array}$ & $\begin{array}{r}-0.8228 \\
(0.019)\end{array}$ & $\begin{array}{c}5.6997 \\
(0.193)\end{array}$ & $\begin{array}{r}1.8820 \\
(0.151)\end{array}$ & $\begin{array}{r}-0.8228 \\
(0.022)\end{array}$ \\
\hline Ln Estimate & $\begin{array}{r}-0.3739 \\
(0.015)\end{array}$ & $\begin{array}{r}-0.0014 \\
(0.011)\end{array}$ & $\begin{array}{r}1.0541 \\
(0.001)\end{array}$ & $\begin{array}{r}-0.3767 \\
(0.015)\end{array}$ & $\begin{array}{r}-0.0014 \\
(0.006)\end{array}$ & $\begin{array}{r}1.0541 \\
(0.001)\end{array}$ \\
\hline Ln Working Days & $\begin{array}{l}0.2765 \\
(0.021)\end{array}$ & $\begin{array}{r}-0.0283 \\
(0.018)\end{array}$ & $\begin{array}{r}-0.0049 \\
(0.002)\end{array}$ & $\begin{array}{l}0.2813 \\
(0.021)\end{array}$ & $\begin{array}{r}-0.0283 \\
(0.019)\end{array}$ & $\begin{array}{r}-0.0049 \\
(0.002)\end{array}$ \\
\hline Estimate/Reserve_Price & $\begin{array}{r}-2.8037 \\
(0.200)\end{array}$ & $\begin{array}{r}-2.5396 \\
(0.158)\end{array}$ & $\begin{array}{r}-0.0188 \\
(0.013)\end{array}$ & $\begin{array}{r}-2.7803 \\
(0.200)\end{array}$ & $\begin{array}{r}-2.5395 \\
(0.158)\end{array}$ & $\begin{array}{r}-0.0188 \\
(0.013)\end{array}$ \\
\hline Nbid-Fringe & $\begin{array}{r}0.025 \\
(0.006)\end{array}$ & $\begin{array}{l}0.0049 \\
(0.008)\end{array}$ & $\begin{array}{l}0.0011 \\
(0.001)\end{array}$ & $\begin{array}{r}0.0258 \\
(0.007)\end{array}$ & $\begin{array}{r}0.0049 \\
(0.006)\end{array}$ & $\begin{array}{r}0.0011 \\
(0.001)\end{array}$ \\
\hline Distance & $\begin{array}{l}0.0559 \\
(0.003)\end{array}$ & & & $\begin{array}{l}0.0562 \\
(0.003)\end{array}$ & & \\
\hline \# of Plants within the Region & $\begin{array}{r}-0.3144 \\
(0.026)\end{array}$ & & & $\begin{array}{r}-0.3159 \\
(0.027)\end{array}$ & & \\
\hline Backlog & $\begin{array}{l}0.0721 \\
(0.015)\end{array}$ & & & $\begin{array}{l}0.0803 \\
(0.016)\end{array}$ & & \\
\hline Sum_Distance & $\begin{array}{r}0.0015 \\
(0.001)\end{array}$ & $\begin{array}{l}0.0002 \\
(0.001)\end{array}$ & $\begin{array}{r}-0.0004 \\
(0.000)\end{array}$ & $\begin{array}{r}0.0015 \\
(0.001)\end{array}$ & $\begin{array}{r}0.0002 \\
(0.001)\end{array}$ & $\begin{array}{r}-0.0004 \\
(0.000)\end{array}$ \\
\hline $\begin{array}{l}\text { Sum_\# of Plants within the Region } \\
\text { Sum_Backlog }\end{array}$ & $\begin{array}{l}0.1242 \\
(0.012) \\
0.0108\end{array}$ & $\begin{array}{r}-0.0262 \\
(0.013) \\
0.0278\end{array}$ & $\begin{array}{r}-0.0129 \\
(0.002) \\
-0.0022\end{array}$ & $\begin{array}{l}0.1271 \\
(0.012) \\
0.0128\end{array}$ & $\begin{array}{r}-0.0262 \\
(0.014) \\
0.0277\end{array}$ & $\begin{array}{r}-0.0129 \\
(0.002) \\
-0.0022\end{array}$ \\
\hline Backlog_Firm_1 & $(0.006)$ & $(0.007)$ & $(0.001)$ & $\begin{array}{r}(0.006) \\
-0.0497 \\
(0.045)\end{array}$ & (0.007) & (0.001) \\
\hline Backlog_Firm_2 & & & & $\begin{array}{l}0.0530 \\
(0.035)\end{array}$ & & \\
\hline Backlog_Firm_3 & & & & $\begin{array}{l}0.0274 \\
(0.026)\end{array}$ & & \\
\hline Backlog_Firm_4 & & & & $\begin{array}{l}0.0777 \\
(0.059)\end{array}$ & & \\
\hline Backlog_Firm_5 & & & & $\begin{array}{r}-0.2561 \\
(0.045)\end{array}$ & & \\
\hline Backlog_Firm_6 & & & & $\begin{array}{r}-0.0416 \\
(0.056)\end{array}$ & & \\
\hline Backlog_Firm_7 & & & & $\begin{array}{r}-0.0526 \\
(0.046)\end{array}$ & & \\
\hline Backlog_Firm_8 & & & & $\begin{array}{l}0.2264 \\
(0.050)\end{array}$ & & \\
\hline Backlog_Firm_9 & & & & $\begin{array}{r}-0.0375 \\
(0.028)\end{array}$ & & \\
\hline
\end{tabular}


Table 4: Estimates of Efficiency Losses

\begin{tabular}{|c|c|c|c|c|c|c|}
\hline \multirow[b]{2}{*}{ Variable } & \multicolumn{5}{|c|}{ Range of Engineers' Estimate (in $\$ 1,000$ ) } & \multirow[t]{2}{*}{ Overall } \\
\hline & {$[0,100]$} & $(100,400]$ & $(400,1000]$ & $(1000,5000]$ & $(5000,]$. & \\
\hline \multicolumn{7}{|l|}{ All Contracts: } \\
\hline $\begin{array}{l}\text { Number of Contracts } \\
\text { Prob of an Inefficiency } \\
\text { Average Efficiency Loss }\end{array}$ & $\begin{array}{r}49 \\
0.03 \\
0.08\end{array}$ & $\begin{array}{r}893 \\
0.53 \\
0.13\end{array}$ & $\begin{array}{l}525 \\
0.17 \\
0.18\end{array}$ & $\begin{array}{l}545 \\
0.27 \\
0.23\end{array}$ & $\begin{array}{l}184 \\
0.33 \\
0.32\end{array}$ & $\begin{array}{r}2196 \\
0.35 \\
0.18\end{array}$ \\
\hline \multicolumn{7}{|c|}{ Contract Won by a Regular Bidder: } \\
\hline $\begin{array}{l}\text { Number of Contracts } \\
\text { Prob of an Inefficiency } \\
\text { Average Efficiency Loss * }\end{array}$ & $\begin{array}{r}1 \\
0.44 \\
1.00\end{array}$ & $\begin{array}{r}90 \\
0.14 \\
0.24\end{array}$ & $\begin{array}{r}94 \\
0.54 \\
0.22\end{array}$ & $\begin{array}{l}147 \\
0.36 \\
0.18\end{array}$ & $\begin{array}{r}42 \\
0.47 \\
0.29\end{array}$ & $\begin{array}{l}374 \\
0.37 \\
0.22\end{array}$ \\
\hline \multicolumn{7}{|c|}{ Contract Won by a Fringe Bidder: } \\
\hline $\begin{array}{l}\text { Number of Contracts } \\
\text { Prob of an Inefficiency } \\
\text { Average Efficiency Loss }\end{array}$ & $\begin{array}{r}48 \\
0.02 \\
0.06\end{array}$ & $\begin{array}{r}803 \\
0.58 \\
0.12\end{array}$ & $\begin{array}{l}431 \\
0.09 \\
0.17\end{array}$ & $\begin{array}{l}398 \\
0.24 \\
0.26\end{array}$ & $\begin{array}{l}142 \\
0.29 \\
0.32\end{array}$ & $\begin{array}{r}1822 \\
0.35 \\
0.17\end{array}$ \\
\hline
\end{tabular}

*Efficiency losses are reported as a fraction of the engineers' estimate. 
FIGURE 1: BID DISTRIBUTION FUNCTION

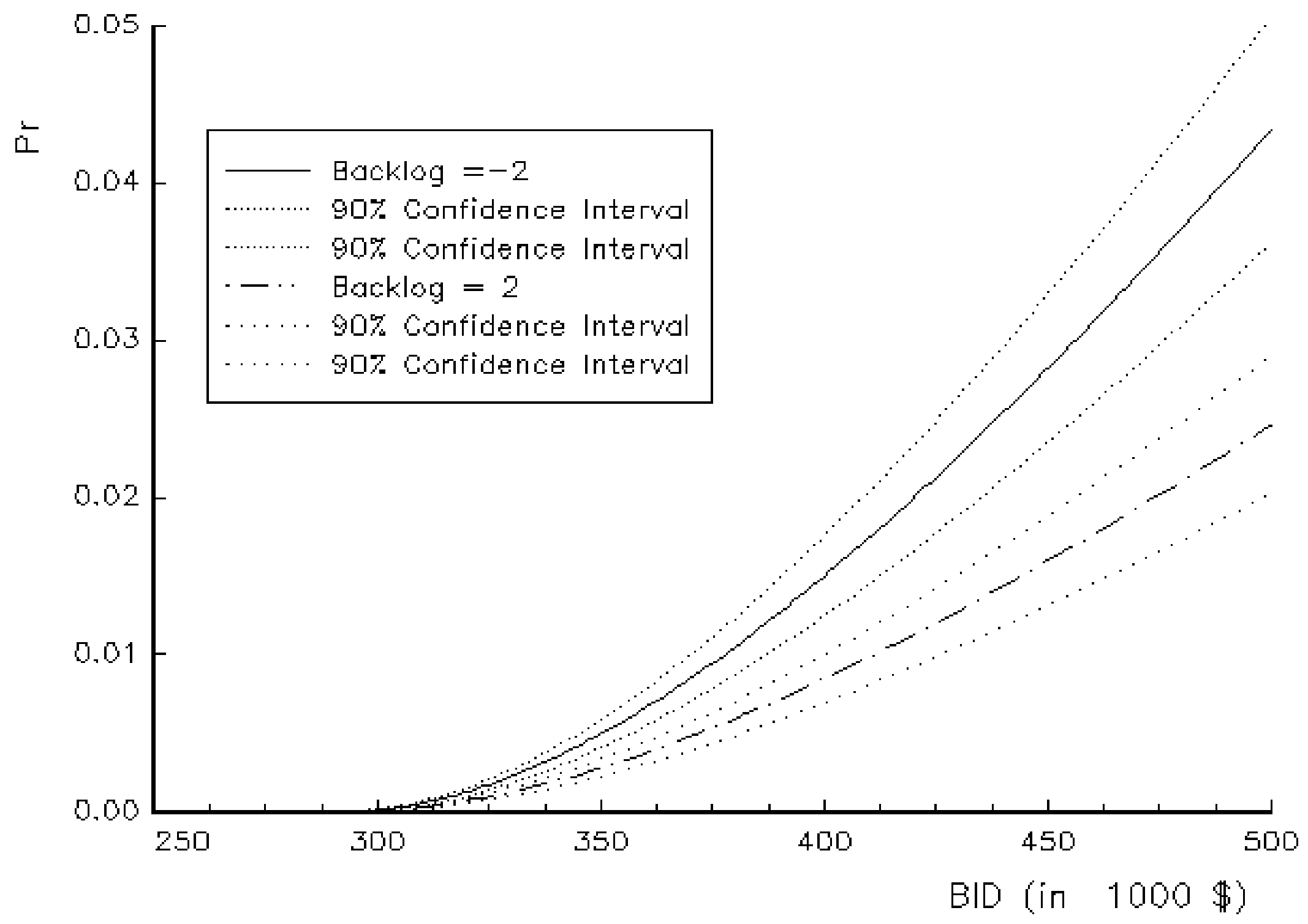


FIGURE 2: VALUE FUNCTION

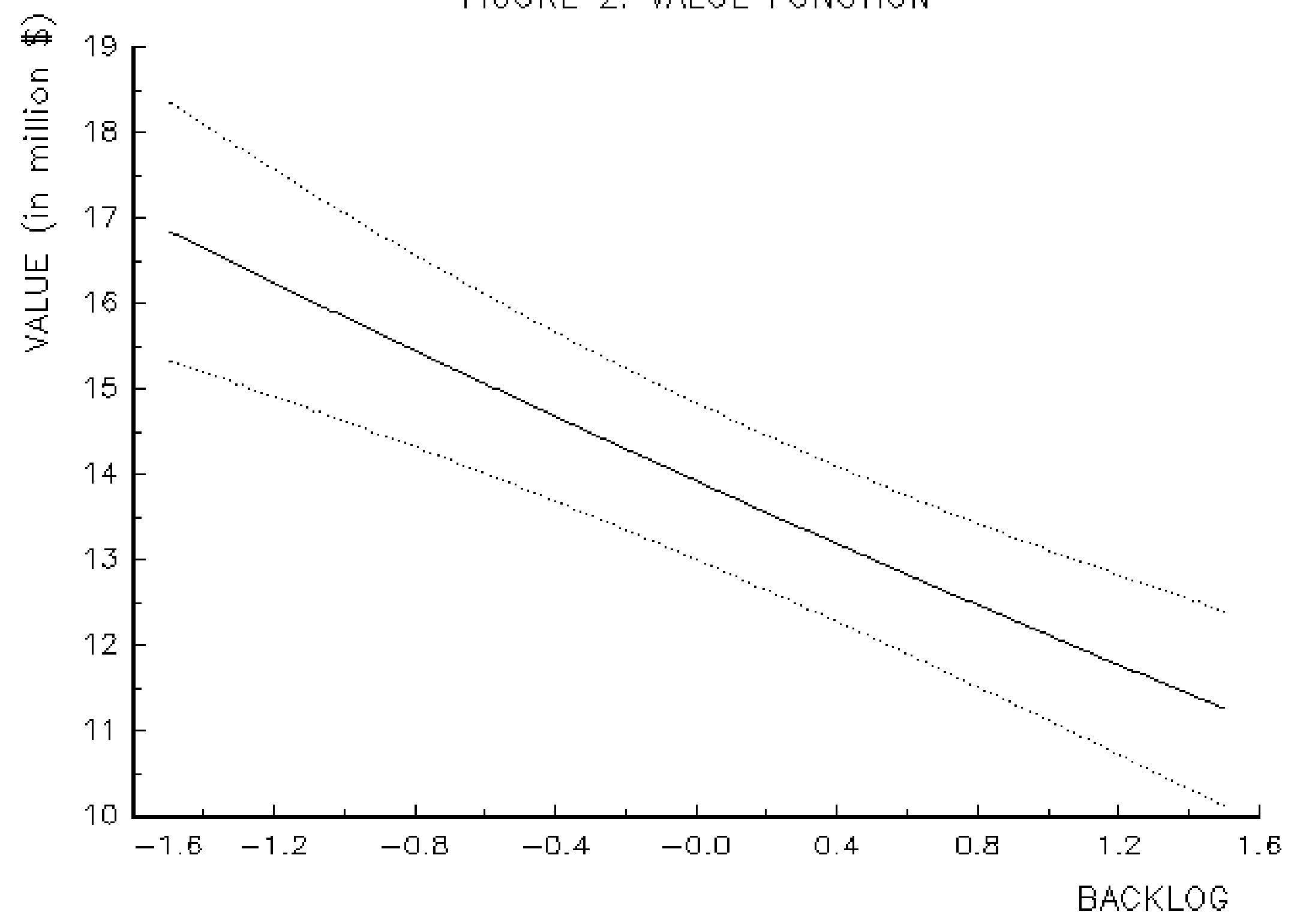




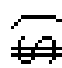

8

๑ 700

650

$\sqsubseteq 600$

뭄 550 500

450

400

350

300

250

200

150

100

50

0

0

FIGURE 3: BID FUNCTION

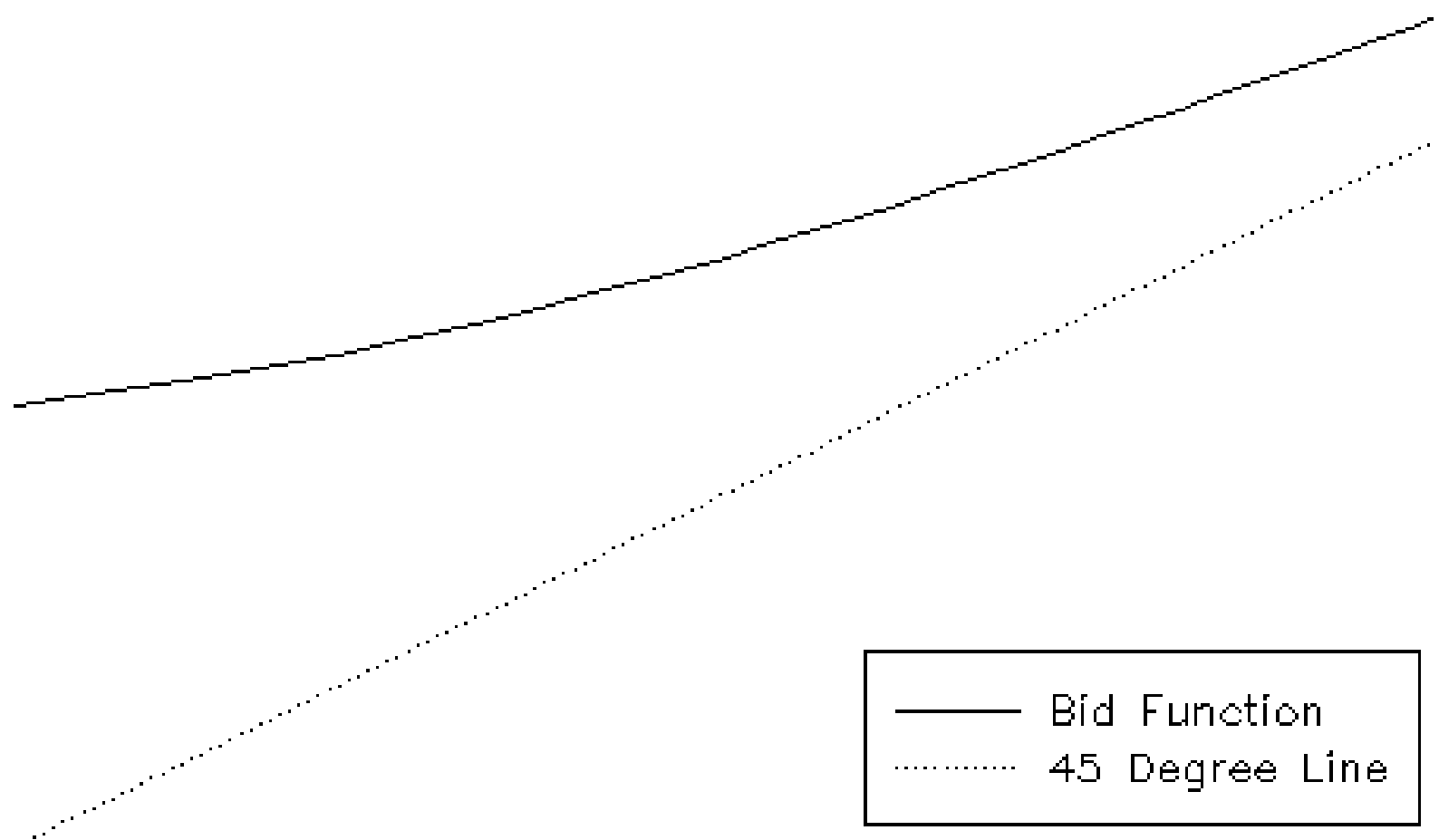


FIGURE 4: COST DISTRIBUTION FUNCTION

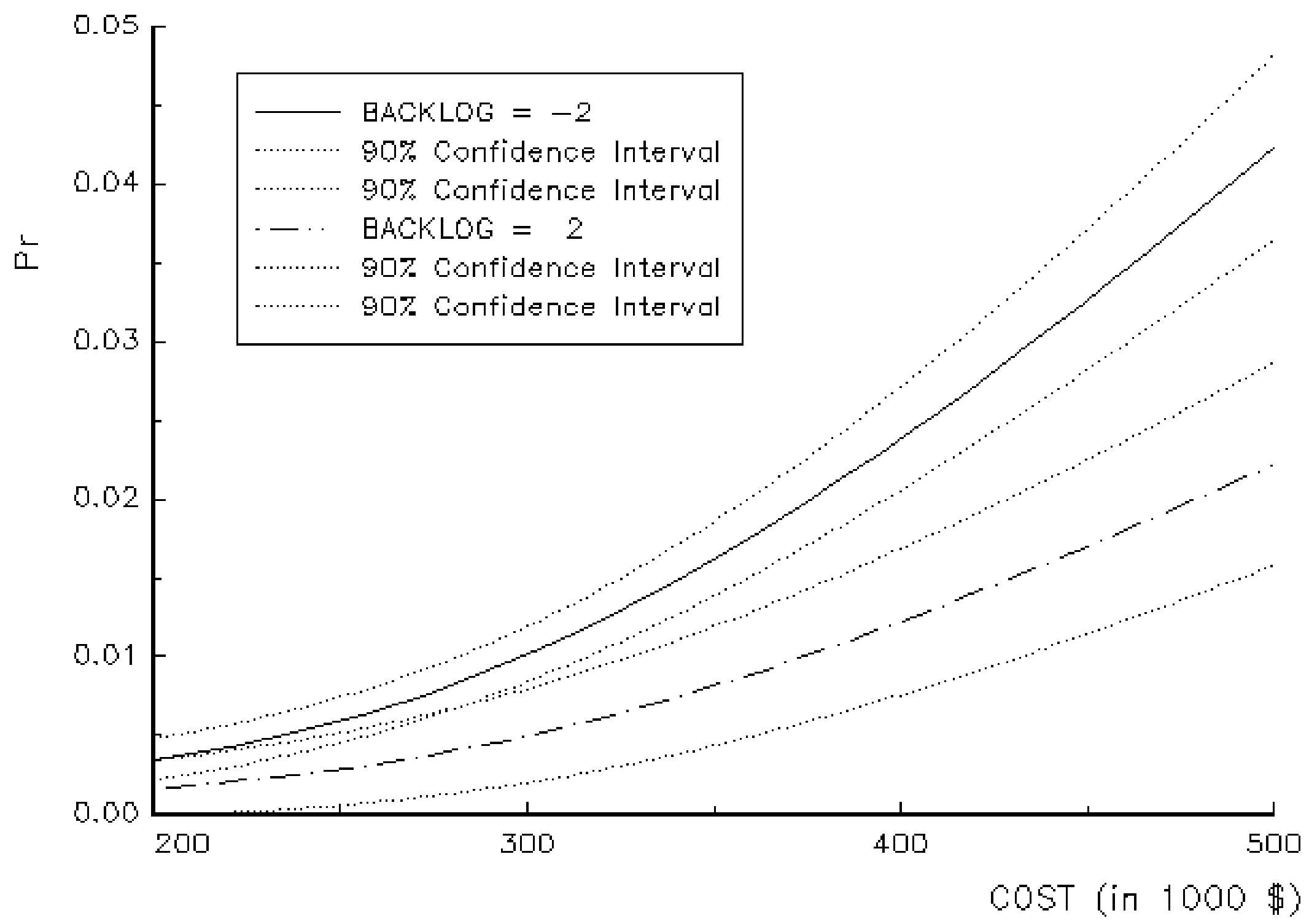

